\title{
DESCRIPCIÓN DE UNA NUEVA ESPECIE DE TROPINOTA MULSANT, 1842 DEL SUBGÉNERO EPICOMETIS BURMEISTER, 1842 DEL NORTE DE MARRUECOS (COLEOPTERA: SCARABAEIDAE, CETONIINAE)
}

\author{
José L. Ruiz \\ Instituto de Estudios Ceutíes, Paseo del Revellín, 30.51001 Ceuta, España. E-mail: euserica@hotmail.com \\ urn:Isid:zoobank.org:author:D633356A-58DA-442D-B726-F3EF7B53D4BF
}

\section{RESUMEN}

Se describe una especie nueva del género Tropinota Mulsant, 1842 a partir de ejemplares del noroeste de Marruecos (región de Tánger-Tetuán): T. iec sp. n. Esta nueva especie se adscribe al subgénero Epicometis Burmeister, 1842 por presentar los principales caracteres diagnósticos del mismo: pronoto sin áreas lisas y la $5^{\mathrm{a}}$ interestría no fuertemente elevada a modo de costilla ni bifurcada en la base. Se definen los rasgos diagnósticos de T. iec sp. n. y se discuten los caracteres diferenciales respecto a las demás especies de Epicometis. La especie morfológicamente más afín a T. iec sp. n. es Tropinota (Epicometis) hirta (Poda von Neuhaus, 1761), de la que se segrega principalmente por el brillo del tegumento, la densidad de la pilosidad corporal, el punteado del pronoto y élitros, la longitud de los tarsos y el punteado de la placa mesosternal, así como por la estructura del edeago, con los parámeros marcadamente ensanchados en la región apical en la primera. De igual forma, se señalan las principales diferencias morfológicas entre la nueva especie y las otros dos taxones específicos del género presentes en el norte de África: T. (Tropinota) squalida (Scopoli, 1763) y T. (Hemiopta) bleusei (Bedel, 1896). Por último, se discute la presencia de T. hirta en Marruecos, donde posiblemente haya sido confundida con T. iec sp. $\mathbf{n}$.

urn:Isid:zoobank.org:pub:222B4C3F-1A14-4357-B8AC-C5CA2EECCDD8

Palabras clave: Coleoptera; Scarabaeidae; Cetoniinae; Tropinota; Epicometis; nueva especie; Marruecos; norte de África; taxonomía.

\section{ABSTRACT}

Description of a new species of Tropinota Mulsant, 1842, subgenus Epicometis Burmeister, 1842, from northern Morocco (Coleoptera: Scarabaeidae, Cetoniinae)

A species of the genus Tropinota Mulsant, 1842, T. iec sp. $\mathbf{n}$., is described using specimens from northwestern Morocco (region of Tangier-Tetouan). This new species is included in subgenus Epicometis Burmeister, 1842 , because it shows the main diagnostic characters of the subgenus: pronotum without smooth areas and 5th interstria not strongly elevated as a keel and not bifurcated at the base. Diagnostic traits of $T$. iec sp. n. are defined, and differential characters with respect to all other species of Epicometis discussed. Based on morphological traits, the closest species to T. iec sp. n. is Tropinota (Epicometis) hirta (Poda von Neuhaus, 1761). Tropinota iec sp. n. differs from $T$. hirta in tegument shine, density of corporal pilosity, pronotal and elytral punctuation, tarsal length, punctuation of the mesosternal plate, and also in the structure of the aedeagus, with parameri clearly widening along the apical region in $T$. iec. Main morphological differences between the new species and the other two species of Tropinota inhabiting northern Africa, T. (Tropinota) squalida (Scopoli, 1763) and T. (Hemiopta) bleusei (Bedel, 1896), are also indicated. Finally, the presence of T. hirta in Morocco, where possibly it has been confused with $T$. iec sp. n., is also discussed.

Key words: Coleoptera; Scarabaeidae; Cetoniinae; Tropinota; Epicometis; new species; Morocco; northern Africa; taxonomy.

Cómo citar este artículo/Citation: Ruiz, J. L., 2015. Descripción de una nueva especie de Tropinota Mulsant, 1842 del subgénero Epicometis Burmeister, 1842 del norte de Marruecos (Coleoptera: Scarabaeidae, Cetoniinae). Grael/sia, 71(1): e019. http://dx.doi.org/10.3989/graellsia.2015.v71.122. 


\section{Introducción}

Desde mediados de la década de 2000, el género Tropinota Mulsant, 1842 viene siendo objeto de revisión parcial y análisis crítico, lo que ha propiciado, por un lado, la descripción de algunas especies nuevas en regiones cuya fauna de Scarabaeoidea es relativamente bien conocida (Tropinota ilariae Dutto, 2007, de Israel; Tropinota paulae Leo, 2010, de Cerdeña) y, por otro, la reconsideración del estatus taxonómico de ciertas especies (Keith, 2006; Sabatinelli et al., 2010); no obstante, estos estudios no han concernido, hasta el momento, a la representación norteafricana del género.

En su concepción actual, Tropinota [especie-tipo: Tropinota reyi Mulsant, 1842, sinónimo más moderno de Scarabaeus squalidus Scopoli, 1763, por designación posterior de Medvedev (1964); véase Branco (2007)] agrupa a un total de 11 especies (de ellas, $T$. hirta con 4 subespecies; T. spinifrons, con 2, y $T$. squalida, con 3) y presenta una distribución general europeo-mediterráneo-turánica, con la mayor diversidad específica en el mediterráneo oriental y oriente medio (e.g. Smetana, 2006; Dutto, 2007; Leo, 2010). Tradicionalmente, la mayoría de los autores admiten tres subgéneros, mantenidos como válidos recientemente por Smetana (2006): Epicometis Burmeister, 1842 [especie-tipo: Scarabaeus hirtellus Linnaeus, 1767, por designación posterior de Arrow (1910); véase Branco (2007)], Hemiopta Bedel, 1896 (especie-tipo: Epicometis bleusei Bedel, 1896, por designación original) y Tropinota. Sin embargo, la taxonomía interna del género es difícil de abordar en su conjunto (Baraud, 1984), y algunos autores han cuestionado esta división subgenérica, sobre todo en lo que respecta a Tropinota y Epicometis, que a veces se han considerado sinónimos o cuando menos de discutible validez (e.g. Horion, 1958; Paulian, 1959; Medvedev, 1964; Báguena, 1967; Paulian \& Baraud, 1982; Baraud, 1985). En efecto, como expone de forma sintética Dutto (2007), la mayoría de los caracteres propuestos como diagnósticos o discriminantes entre ambos subgéneros a veces son muy sutiles, de difícil apreciación y se encuentran sujetos a alta variabilidad intra- e interpoblacional, por lo que según Crovetti (1973) sólo resultan válidos si se ponderan de manera conjunta.

Hasta el momento, no se ha propuesto una filogenia del género y las relaciones filogenéticas entre las especies atribuidas a cada subgénero son desconocidas. En este sentido, no se ha generado todavía información consistente que apoye la actual taxonomía interna de Tropinota, cuestión que habría de afrontarse desde varios enfoques metodológicos, integrando caracteres moleculares para la resolución de la filogenia y sistemática del género. Sin embargo, a pesar de las inciertas relaciones filogénéticas y la controvertida validez de los subgéneros, esta subdivisión es de indudable utilidad para diferenciar grupos de especies, en principio artificiales, en el seno de Tropinota.

En el norte de África sólo se conocen dos especies del subgénero Epicometis: T. (E.) hirta (Poda von Neuhaus, 1761), de amplia distribución europeacaucásica que alcanza por el este oriente próximo e Irán y ha sido registrada puntualmente en Marruecos (e.g. Baraud, 1977, 1984, 1985, 1992; Miksic, 1982; Paulian \& Baraud, 1982; Krajcik, 1998; Bunalski, 1999; Dutto, 2005; Smetana, 2006, Tauzin \& Rittner, 2012) y $T$. (E.) annabrunae (Crovetti, 1973), conocida sólo del noroeste de Libia (Crovetti, 1973; Baraud, 1985; Smetana, 2006). Además, en el África paleártica se encuentran presentes otras dos especies del género: T. (T.) squalida (Scopoli, 1763), especie politípica, con cuatro subespecies reconocidas, de extensa distribución circunmediterránea y representada en el Magreb por la subespecie T. (T.) squalida pilosa (Brullé, 1832) (e.g. Baraud, 1985, 1992; Krajcik, 1998; Smetana, 2006), y T. (Hemiopta) bleusei (Bedel, 1896), exclusiva de las regiones predesérticas del sur de Argelia (Bedel, 1896; Reitter, 1913; Baraud, 1985; Smetana, 2006).

En el caso de $T$. (E.) hirta, las primeras citas para Marruecos son relativamente recientes, aunque basadas en muy escaso material de antigua captura, y se deben a Baraud (1985: addendum, 629-630) que la señala con ciertas dudas de dos localidades, Tetuán y KasbaTadla (entre Fez y Marraquech). Posteriormente, tan solo Chavanon (2002) la reseñó de las montañas de Beni Snassen y de la Desembocadura del río Muluya (=Oued Moulouya), en el Marruecos nororiental, aunque expresa la necesidad de confirmar estas citas. Por último, Baraud (1992) la señaló genéricamente de Marruecos, en donde la califica como (sic) "trés rare". La presencia de T. (E.) hirta en Marruecos es recogida, igualmente de forma genérica, por Smetana (2006).

A tenor de la supuesta rareza de $T$. (E.) hirta en Marruecos y del interés en confirmar con datos recientes su presencia en el norte del país, durante los últimos 10 años hemos muestreado activamente diversas regiones del Rif occidental, a fin de detectar núcleos poblacionales de esta especie. Así, entre 2003 y 2013 hemos hallado sólo un total de 7 individuos en tres localidades (dos de ellas muy cercanas entre sí), en principio asignables a esta especie. Sin embargo, el estudio comparado de estos ejemplares con material de T. (E.) hirta procedente de Europa, nos lleva a considerar a estas poblaciones normarroquíes como pertenecientes a una especie distinta e inédita de Tropinota del subgénero Epicometis, bien diferenciada de la primera tanto por caracteres morfológicos externos como de la genitalia masculina.

El objetivo de este trabajo es la descripción de esta nueva especie de Tropinota de Marruecos, ofreciendo sus rasgos diagnósticos y discriminantes respecto a las demás especies mediterráneo occidentales morfológicamente afines. Asimismo, se indican los caracteres 
morfológicos que la separan del resto de especies norteafricanas del género Tropinota y se discute la presencia de $T$. (E.) hirta en Marruecos, que podría haber sido confundida con la nueva especie que aquí se describe.

\section{Material y métodos}

La descripción de la especie nueva de Tropinota se basa en un total de 7 ejemplares, 4 machos y 3 hembras, colectados en tres localidades del noroeste de Marruecos (Rif occidental) y conservados en seco. El holotipo macho y 4 paratipos ( 2 machos y 2 hembras) se han depositado en la colección de entomología del Museo Nacional de Ciencias Naturales, Madrid, CSIC, España (MNCN), y 2 paratipos (un macho y una hembra) en la colección J.L. Ruiz, Ceuta, España (JLR). Como material de comparación de T. (E.) hirta se han estudiado un total de 20 ejemplares procedentes de España (10 ejs.; parte de este material ibérico fue estudiado por Báguena, 1967), Francia (2 ejs.), Italia (2 ejs.), Hungría (2 ejs.), Bulgaria (2 ejs.), Rumania (1 ej.) e isla de Creta, Grecia (1 ej.), cuyos datos de captura y colecciones en las que se encuentran depositados se relacionan en el Apéndice 1. En cuanto a las demás especies mediterráneas del subgénero Epicometis y el único taxón específico integrado en Hemiopta, los caracteres discriminantes utilizados han sido extraídos de la bibliografía citada en el apartado "Discusión", por ser estos lo suficientemente claros y encontrarse adecuadamente ilustrados.

El estudio morfológico se efectuó sobre ejemplares conservados en seco, mediante observación con estereomicroscopio. Las genitalias masculinas, extraídas a ejemplares frescos (especie nueva) o secos previamente rehidratados (material de comparación), se montaron en cartulinas con resina DMHF, las cuales se pincharon con su respectivo ejemplar. Las fotografías se realizaron con cámara digital. Las medidas se efectuaron con micrómetro acoplado a uno de los oculares.

La longitud total de los ejemplares se ha tomado desde el extremo anterior del clípeo (en posición dorsal, con la cabeza extendida) hasta el extremo posterior de los élitros. Para cuantificar el aspecto corporal (más o menos robusto) se ha empleado el "índice formal absoluto" (i.f.a.), ya utilizado por Dutto (2007) y Leo (2010) en Tropinota, que se calcula según la siguiente fórmula: i.f.a. $=$ L./le. $\times$ Lp./lp., donde: "L." es la longitud del insecto medida desde el extremo del ángulo anterior del pronoto al ápice del élitro, "le." es la máxima anchura de los élitros medida transversalmente, "Lp." indica la longitud del pronoto en la línea media, y "lp." la anchura máxima del pronoto (véase Dutto, 2007). La longitud de las metatibias (tomada de la pata posterior izquierda) se ha medido en la arista superior en visión lateral, desde el punto de inserción en el metafémur hasta el extremo del diente apical superior, y la longitud del metatarso desde el punto de inserción en la metatibia hasta el extremo del último tarsómero, sin incluir las uñas, con el metatarso lo menos curvado posible.

El concepto de especie adoptado es el denominado "concepto evolutivo" (Wiley, 1978, 1981; Wiley \& Mayden, 2000), en el que, básicamente, una especie puede definirse como un linaje de poblaciones único que mantiene su identidad respecto a otros linajes y que tiene sus propias tendencias evolutivas y devenir histórico.

Desde un punto de exclusivamente práctico o expositivo, y al objeto de separar grupos de especies morfológicamente afines, seguimos el esquema taxonómico tradicional del género, que integra a tres subgéneros en el seno de Tropinota (Epicometis, Tropinota y Hemiopta), aunque asumiendo los comentarios críticos al respecto efectuados por diversos autores, especialmente Crovetti (1973), Baraud (1984) y Dutto (2007). En cuanto a la composición específica y subespecífica del género, seguimos en líneas generales la expuesta por Smetana (2006), con las adiciones y modificaciones puntuales posteriores (Dutto, 2007; Leo, 2010; Sabatinelli, et al., 2010).

\section{Resultados}

\section{Tropinota (Epicometis) iec sp. n.}

(Figs. 1-10)

urn:1sid:zoobank.org:act:DDCC3D7B-CD33-4BFF-8A3DA1CC1B421E0E

Material estudiado: HOLOTYPUS: 1 macho (conservado en seco), etiquetado: "Crrtra. Zinat-Mulay Abdeselam P-4702, Beni Aros, prov. Larache, Marruecos, $35^{\circ} 22^{\prime} 04^{\prime \prime} \mathrm{N} 5^{\circ} 32^{\prime} 17^{\prime \prime} \mathrm{O}$, 513 m, 27-V-2006, J.L. Ruiz leg." (etiqueta blanca, impresa); "Holotypus, Tropinota (Epicometis) iec, J.L. Ruiz des. 2014" (etiqueta roja, impresa). Depositado en col. MNCN (MNCN Cat. tipos $\left.n^{\circ} 2599\right)$.

PARATYPI: 3 machos y 3 hembras (conservados en seco), etiquetados: 1 macho: "Ifahsa, Garganta del Oued Laou, Crrtra. P-4105, prov. Tetuán, Marruecos, 190 m, 35 $17^{\circ} 36^{\prime \prime} \mathrm{N} 5^{\circ} 13^{\prime} 47^{\prime \prime} \mathrm{O}$, 28-V-2006, J.L. Ruiz leg." (etiqueta blanca, impresa); 1 macho: "Crrtra. Zinat-Mulay Abdeselam P-4702, Beni Aros, prov. Larache, Marruecos, $35^{\circ} 22^{\prime} 04^{\prime \prime} \mathrm{N} 5^{\circ} 32^{\prime} 17^{\prime \prime} \mathrm{O}, 512 \mathrm{~m}, 20-\mathrm{V}-2007$, J.L. Ruiz leg." (etiqueta blanca, impresa); 1 hembra: "Crrtra. ZinatMulay Abdeselam P-4702, Beni Aros, prov. Larache, Marruecos, $35^{\circ} 22^{\prime} 04^{\prime \prime N} 5^{\circ} 32^{\prime} 17^{\prime \prime} \mathrm{O}, 513 \mathrm{~m}, 12-\mathrm{V}-2012$, J.L. Ruiz leg." (etiqueta blanca, impresa); 1 macho y 2 hembras: "Beni Ferten, Oued Laou, Crrtra. P-4105, Prov. Tetuán, Marruecos, $35^{\circ} 21^{\prime} \mathrm{N} 5^{\circ} 10^{\prime} \mathrm{O}, 37 \mathrm{~m}$, 26-V-2013, J.L. Ruiz leg." (etiqueta blanca, impresa). Todos los paratipos portan la siguiente etiqueta: "Paratypus/Tropinota (Epicometis) iec/J.L. Ruiz des. 2014" (etiqueta roja, impresa). Cuatro paratipos (dos macho y dos hembras) depositados en la col. MNCN (MNCN Cat. tipos $n^{\circ} 2599$ ) y otros dos (macho y hembra) en col. JLR.

DESCRIPCIÓN DEL HOLOTIPO (macho): Longitud total: $12.3 \mathrm{~mm}$. Anchura máxima, situada a nivel de la región humeral de los élitros: $6.5 \mathrm{~mm}$. Aspecto general negro, brillante, con pilosidad escasa que deja ver perfectamente el tegumento en la región dorsal 

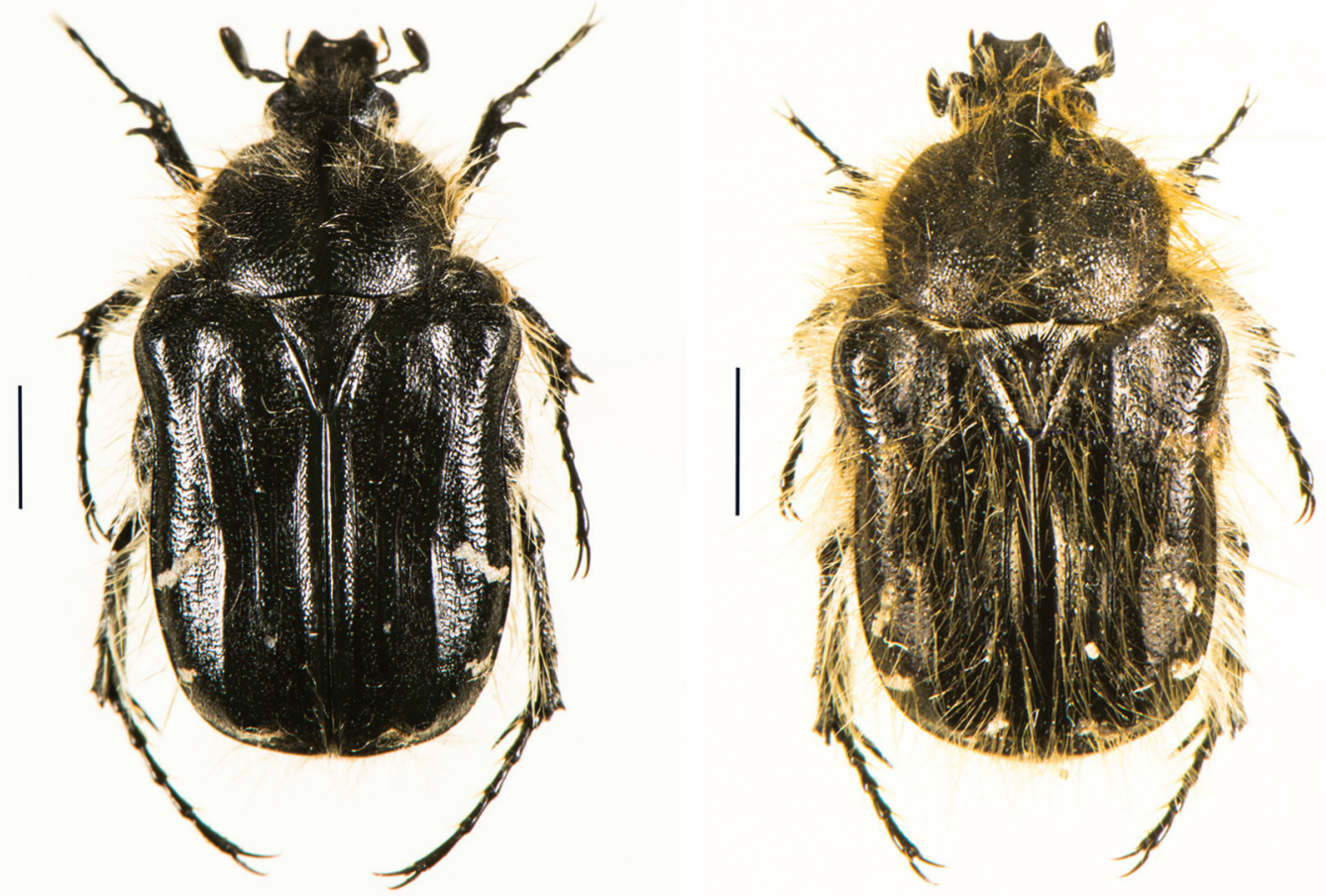

Figs. 1-2.- Habitus en visión dorsal de: 1) Tropinota iec sp. n. (Holotipo, Beni Aros, Marruecos); 2) Tropinota hirta (Poda von Neuhaus, 1761) (Mte. Frassani, Pianello, Italia). Escala: 2 mm. (Fotografías: S. Yubero).

Figs. 1-2.- Habitus, dorsal view, of: 1) Tropinota iec sp. n. (Holotype, Beni Aros, Morocco); 2) Tropinota hirta (Poda von Neuhaus, 1761) (Mte. di Frassani, Pianello, Italy). Scale: 2 mm. (Photos: S. Yubero).

y ventral (Figs. 1, 3). Cuerpo robusto, relativamente ancho, aunque con las patas de aspecto grácil, alargadas; índice formal absoluto ("i.f.a.")=1.26. Tegumento corporal de color negro, brillante, con microrreticulado muy débil, no enmascarado por la pilosidad, que es fina y de color blanquecino-amarillento, escasa en visión dorsal, sobre todo en los élitros, y más densa en el pronoto y región ventral, fácilmente caediza; las manchas elitrales blancas muy reducidas, casi lineales.

Cabeza (Fig. 5) negra, estrecha; clípeo con el margen anterior profundamente escotado en curva regular, con los ángulos antero-laterales bien salientes, en ángulo obtuso, casi recto, romos, redondeados en el ápice y ligeramente levantados; márgenes laterales subparalelos en la mitad basal y convergentes hacia delante en la mitad distal, con las mejillas algo elevadas a nivel de las inserciones antenales; disco del clípeo un poco elevado por delante de la unión clípeo-frontal, que no presenta sutura perceptible; frente levemente hundida en el centro. Punteado de la cabeza de aspecto subrugoso, constituida por puntos finos y muy densos, confluentes; los puntos del clípeo un poco más gruesos que los de la frente, con los bordes levantados, de modo que ofrece un aspecto casi reticulado, el punteado frontal más fino y muy denso, más espaciado hacia el vértex y genas. Pilosidad escasa, blanquecina-amarillenta y concentrada en la región frontal (posiblemente perdida en parte por rozamiento). Ojos globulares y no muy salientes, con el canto ocular estrecho y apenas alcanzando la mitad del ojo.

Antenas de coloración castaño muy oscuro, casi negro, de diez artejos, con la maza apical constituida por los tres últimos artejos. Longitud del escapo (primer artejo antenal): $0.57 \mathrm{~mm}$; longitud del funículo (artejos $2^{\circ}$ a $7^{\circ}$, ambos inclusive): $0.72 \mathrm{~mm}$; longitud de la maza antenal: $1.11 \mathrm{~mm}$; relación "longitud escapo+funículo/ longitud maza antenal": 1.16. Primer artejo o escapo negro, troncocónico, muy ensanchado hacia el extremo y acodado ventralmente, con escasos pelos erectos en su región posterior; segundo artejo subgloboso, castaño muy oscuro, ralo; tercer artejo semicónico, grueso, con algunos pelos cortos en su cara posterior; cuarto a sexto subcilíndricos, anchos y cortos, casi fusionados entre sí, con muy contados pelos erectos y dispersos; séptimo muy transverso, cuneiforme, embutido entre el sexto y la base de la maza antenal (base del octavo artejo); maza antenar de color castaño muy oscuro, con el artejo central (noveno antenómero) ligeramente más corto que los dos contiguos, los artejos de contorno subelíptico, con la cara externa de la maza brillante y desprovista de pilosidad, la interna con una estrecha franja pilosa central curvada, con pelos muy cortos y relativamente gruesos, castaño-amarillentos, semitumbados y dirigidos hacia arriba. 

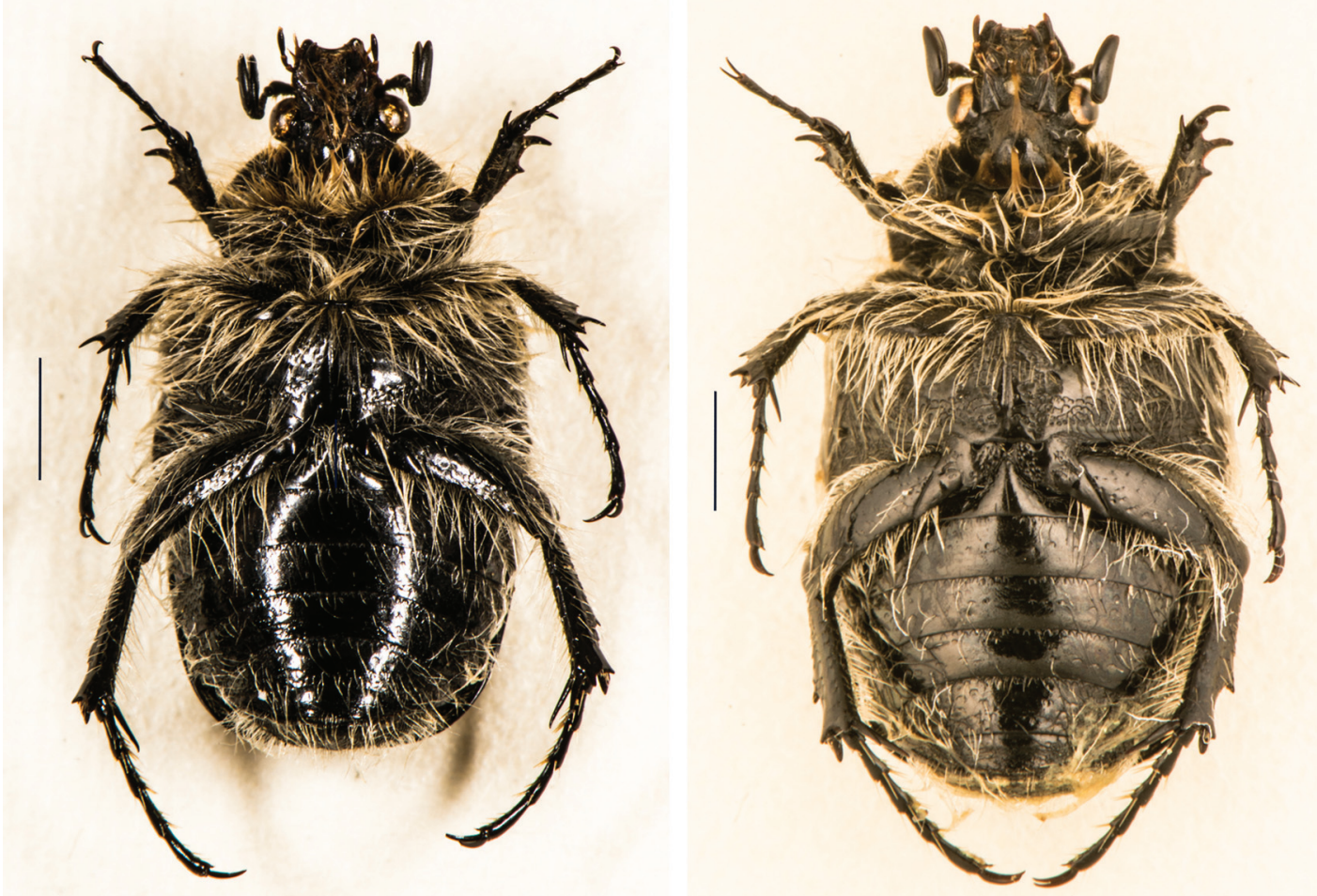

Figs. 3-4.- Habitus en visión ventral de: 3) Tropinota iec sp. n. (Holotipo, Beni Aros, Marruecos); 4) Tropinota hirta (Poda von Neuhaus, 1761) (Mte. di Frassani, Pianello, Italia). Escala: 2 mm. (Fotografías: S. Yubero).

Figs. 3-4.- Habitus, ventral view, of: 3) Tropinota iec sp. n. (Holotype, Beni Aros, Morocco); 4) Tropinota hirta (Poda von Neuhaus, 1761) (Mte. di Frassani, Pianello, Italy). Scale: 2 mm. (Photos: S. Yubero).
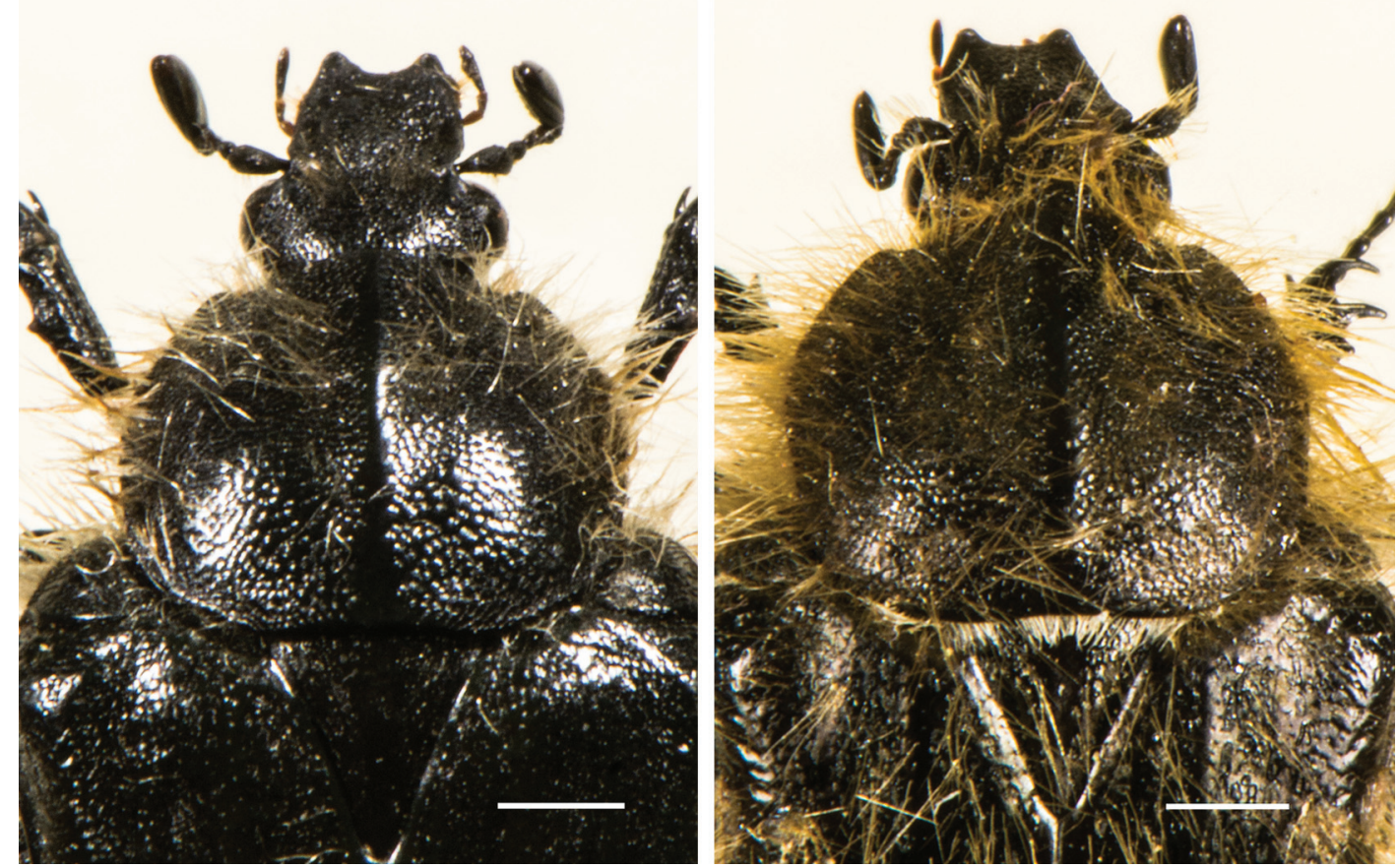

Figs. 5-6.- Cabeza y pronoto de: 5) Tropinota iec sp. n. (Holotipo, Beni Aros, Marruecos); 6) Tropinota hirta (Poda von Neuhaus, 1761) (Mte. di Frassani, Pianello, Italia). Escala: $1 \mathrm{~mm}$. (Fotografías: S. Yubero).

Figs. 5-6.- Head and pronotum of: 5) Tropinota iec sp. n. (Holotype, Beni Aros, Morocco); 6) Tropinota hirta (Poda von Neuhaus, 1761) (Mte. di Frassani, Pianello, Italy). Scale: $1 \mathrm{~mm}$. (Photos: S. Yubero). 
Pronoto (Fig. 5) brillante, de aspecto subcuadrangular, poco transverso, 1.27 veces más ancho que largo (longitud: $3.45 \mathrm{~mm}$, en la línea media), con la máxima anchura aproximadamente en el medio (anchura máxima: $4.4 \mathrm{~mm}$ ), presentando una línea longitudinal media elevada, subcareniforme, lisa y bien patente, algo más ensanchada en el quinto posterior; lados de aspecto redondeados, aunque netamente convergentes en la mitad anterior y subparalelos en la mitad posterior, con los ángulos anteriores obtusos y débilmente prominentes, los posteriores muy ampliamente redondeados; margen anterior convexo en el centro, un poco prolongado hacia delante; base del pronoto ligeramente arqueada por delante del escutelo; márgenes laterales sin reborde aparente, con un punteado fino, denso y difuso, sólo en los ángulos anteriores y en los posteriores se intuye un muy fino reborde corto y difuso. Punteado pronotal grueso pero no muy impreso, ligeramente irregular, constituido por puntos semiestriados, poco profundos y de límites difusos, cada uno de ellos con una incisión fina en forma de semicírculo o media luna en su margen anterior; más denso, subconfluente en la mitad anterior, sobre todo cerca de los ángulos anteriores y márgenes laterales, donde además los puntos son más pequeños, tornándose bastante menos densos y más gruesos en la mitad basal, sobre todo en sendas franjas a ambos lados de la carena central lisa, donde la separación entre ellos es casi igual a su diámetro, apreciándose bien el tegumentos liso y brillante entre los puntos. Pilosidad blanquecina-amarillenta, muy fina, semierecta, siguiendo en líneas generales el patrón del punteado en el que se inserta, más densa en los lados y mitad anterior y prácticamente ausente en la mitad posterior y sobre todo en la base, posiblemente debido a pérdida por rozamiento.

Mesoepímeros salientes, bien visibles en visión dorsal, con punteado denso y de aspecto estriado, subrugoso, similar al de los lados del pronoto aunque con puntos un poco más pequeños, bastante más denso en la región anterior, con pilosidad semejante a la del pronoto, concentrada en la región declive anterior y casi ausente en la región posterior (dorsal).

Escutelo grande y alargado (longitud: $2.6 \mathrm{~mm}$ ), de aspecto brillante, en forma de triángulo isósceles, 1.06 veces más largo que ancho en la base, profunda pero estrechamente asurcado en los lados, con punteado constituido por puntos escasos, en forma de herradura y un poco irregulares, distribuidos mayoritariamente por la región basal y por sólo cuatro-cinco puntos alineados en cada lateral, de forma que queda una amplia región central lisa en la mitad posterior; pilosidad ausente, sólo se observan en tres puntos un cortísimo pelo tumbado que parece ser la base de una queta rota.

Élitros robustos, negros, con tegumento brillante, de aspecto subcuadrangular y muy escasamente pilosos; márgenes laterales enteramente rebordeados, con un borde fino, saliente y liso; longitud máxima: $7.9 \mathrm{~mm}$; anchura máxima (de los dos élitros conjuntamente) situada a nivel de la región humeral: $6.55 \mathrm{~mm}$; relación longitud/anchura máximas: 1.2. Cada élitro presenta cinco manchas blancas perceptibles pero estrechas y poco aparentes, distribuidas desde la zona anterior a la posterior y del exterior al interior de la siguiente forma: una circular pequeña $(0.18 \mathrm{~mm}$ de diámetro $)$ aproximadamente en la $6^{\circ}-7^{\mathrm{a}}$ interestría, por detrás de la región humeral y a nivel del estrechamiento o sinuosidad lateral del élitro; una oblicua, estrecha y transversa (longitud: $0.3 \mathrm{~mm}$, anchura: $1.2 \mathrm{~mm}$; medidas tomadas en el élitro izquierdo), de contorno sinuoso e irregular, desde el borde del élitro hasta aproximadamente la $6^{\mathrm{a}}$ interestría, algo por detrás del medio; otra mancha transversa, pequeña e irregular (longitud: $0.33 \mathrm{~mm}$, anchura: $0.75 \mathrm{~mm}$ ), situada $1.42 \mathrm{~mm}$ por detrás de la anterior, muy cerca de la zona declive apical y con su margen externo casi tocando el borde del élitro; una transversa, corta (longitud: $0.27 \mathrm{~mm}$, anchura: $0.55 \mathrm{~mm}$ ), situada justo por debajo del callo anteapical; y, por último, una muy pequeña y difusa mancha circular (diámetro: $0.2 \mathrm{~mm}$ aproximadamente), muy poco perceptible, situada en el tercio apical de la $3^{\mathrm{a}}$ interestría, ligeramente por encima del nivel de la tercera mancha externa; asimismo, en esta $3^{\mathrm{a}}$ interestría se intuye un muy leve indicio de mancha blanca, apenas perceptible, situado casi en el medio. Superficie de los élitros ligeramente deprimida en el medio, a ambos lados de la interestría parasutural, con la región humeral ligeramente abombada así como la región periescutelar, de forma que entre el húmero y dicha región se observa una poco profunda pero neta depresión difusa; callo anteapical neto, pronunciado y subgiboso, de límites difusos; la primera interestría o parasutural elevada en la región discal e inclinada hacia el exterior. Ninguna de las interestrías fuertemente levantadas o subcostiformes, sólo la $5^{\text {a }}$ se encuentra levemente elevada en el tercio apical. Escultura elitral compleja y en buena parte difusa, sobre todo hacia los márgenes laterales y región apical; se identifican cinco estrías (además de la sutura) con desarrollo irregular, que desaparecen o difuminan tanto en el quinto anterior, a nivel de las zonas elevadas periescutelar y humeral como en la región apical; estrías constituidas por dos surcos finos muy cercanos y subparalelos, más o menos interrumpidas en su recorrido, sobre todo en las zonas anterior y posterior, la $1^{\mathrm{a}}, 2^{\mathrm{a}}$ y $3^{\mathrm{a}}$ llegan hasta la región declive apical, y la $4^{\circ}$ y $5^{\text {a }}$ desaparecen un poco por detrás del medio del élitro, a nivel de la $2^{\mathrm{a}}$ mancha blanca externa. Interestrías con el punteado según se expone en el Apéndice 2. Pilosidad escasísima, conformada por pelos finos y débiles, semirrizados y tumbados, restringida a la base junto al escutelo, a las $2^{\mathrm{a}}$ y $3^{\mathrm{a}}$ manchas blancas externas y a la zona declive apical, en torno al callo anteapical y a la mancha blanca situada debajo de éste, así como algunos dispersos por la superficie elitral; se observa igualmente la base de algunos pelos rotos dispersos. 
Propleuras y prosterno con punteado fuerte y subrugoso, casi ondulado, y pilosidad abundante blanquecinoamarillenta, larga y erecta, la del prosterno dirigida hacia delante y la de las proleuras hacia abajo. Apófisis mesosternal prolongada entre las mesocoxas, apenas sobresaliente hacia delante, subcuadrada, con el margen anterior casi recto, sólo débilmente arqueado en el centro, con un reborde grueso, brillante y liso y una línea de pequeños puntos pilíferos anexa al margen posterior de dicho borde. Placa metasternal muy brillante, con un profundo surco longitudinal mediano que no llega a alcanzar el margen posterior, y punteado fuerte y poco denso, con puntos redondeados similares a los más gruesos del pronoto, separados entre 1.5 y 3 veces su diámetro, más denso en la mitad anterior y dejando dos estrechas bandas lisas subtriangulares a ambos lados del surco medio; metapleuras con punteado distinto a la zona central del metasterno (placa metasternal), de aspecto estriado y subrugoso, semejante al de las propleuras, y pilosidad abundante, larga y erecta, un poco inclinada hacia atrás; metaepímeros muy densamente punteados, con puntos similares a los de las mesopleuras aunque un poco más finos, igualmente con pilosidad densa.

Pigidio rebordeado en todo su contorno, con reborde fino y liso; escultura muy impresa, constituida por puntos estriados y densos, de aspecto subrugoso y ondulado, más densos y fuertes en la zona superior; pilosidad larga, erecta y densa, concentrada mayoritariamente en la mitad superior, justo por debajo del ápice elitral, más corta y mucho menos densa en la mitad inferior.

Abdomen muy brillante (Fig. 3), débilmente hundido en una franja longitudinal mediana muy difusa, lo que le imprime un aspecto ligeramente cóncavo en la región central de los esternitos abdominales visibles $3^{\circ}, 4^{\circ}$ y $5^{\circ}$, y el $6^{\circ}$ un poco más elevado que el anterior. Esternitos abdominales, excepto el $6^{\circ}$ (último visible), con una amplia zona central casi lisa, sólo con una línea de puntos pequeños en forma de herradura junto al margen anterior de cada uno de ellos y algún punto disperso, en las áreas laterales el punteado es similar pero mucho más denso; el $5^{\circ}$ esternito también presenta punteado en la zona central anexa al margen posterior y el $6^{\circ}$ esternito se encuentra punteado en toda su superficie; pilosidad en general escasa y caediza, semierecta, limitada a las zonas laterales, al margen posterior del $5^{\circ}$ esternito y a la totalidad de la superficie del último esternito, con algunos pelos dispersos en las líneas de puntos anexas al margen anterior del resto de esternitos. Márgenes laterales de los terguitos abdominales visibles en visión lateral, los cuales presentan un punteado fino y subrugoso, muy semejante al de las propleuras, con una pilosidad larga, densa y semierecta, a modo de mechón en cada terguito, muy conspicua y bien visible desde arriba.

Patas de aspecto alargado, relativamente gráciles, con los tarsos más largos que las respectivas tibias.
Patas anteriores con los fémures un poco engrosados en su mitad basal, densamente pilosos en su cara superior, con muy escasos pelos en la cara ventral o inferior; protibias tridentadas en su arista lateral externa y una espina apical interna de longitud similar al primer protarsómero, los dientes externos bien desarrollados, largos y semicurvados, el medio situado ligeramente más cerca del distal que del proximal; protarsos largos y estrechos, relación "longitud protarsos (sin incluir las uñas)/longitud protibias (medidas desde la base hasta el extremo del diente apical externo)": 1.03. Patas medias con los fémures ligeramente engrosados en la región central, con una banda de pelos abundantes, largos y semierectos en el margen posterior; mesotibias cortas, robustas, con la superficie subrugosa, ampliamente escotadas en el tercio distal de su arista superior, donde presenta 4 pequeños dientes y uno grande en el comienzo de la escotadura, ápice con tres fuertes dientes espiniformes (dos se encuentran en el extremo de su cara externa y otro en el borde posterior de la arista superior) y dos espinas apicales internas alargadas, situadas juntas, ligeramente más largas que el $2^{\circ}$ mesotarsómero; relación "longitud mesotarsos (sin incluir las uñas)/longitud mesotibias (medidas desde la base hasta el extremo del diente apical externo)": 1.44. Patas posteriores con fémures ligeramente arqueados y máxima anchura en el tercer cuarto distal, los cuales presentan un denso punteado en el margen anterior de la cara ventral y aristas anterior y posterior, y una línea de puntos irregular en el margen posterior, con pilosidad densa asociada al punteado, erecta, dirigida hacia delante en la región anterior y hacia atrás en la posterior, de forma que existe una amplia banda central lisa; metatibias con un fuerte diente en su arista dorsal situado aproximadamente en el tercer cuarto apical, tres dientes apicales, uno dorsal, otro en el medio de la cara externa y otro ventral, así como dos robustas espinas apicales internas, la superior recta y de longitud casi igual a los dos primeros metatarsómeros, la inferior débilmente curvada y un poco más corta que la superior; metatarsos delgados y largos (Fig. 7), relación "longitud metatarsos (sin incluir las uñas)/longitud metatibias (medidas desde la base hasta el extremo del diente apical superior)": 1.22. Uñas de los tarsos estrechas y alargadas, débilmente curvadas.

Edeago con la falobase un poco más larga que los parámeros, más ancha en la mitad proximal; relación "longitud falobase/longitud parámeros" (en medición lateral): 1.06; parámeros (Fig. 9), en visión dorsal, de aspecto robusto, con los lados externos convergentes hasta la mitad y a partir de aquí marcadamente ensanchados hacia el extremo donde son redondeados, lados internos arqueados de manera que el espacio entre ellos es fusiforme; en visión ventral, los parámeros son membranosos. Spiculum gastral relativamente estrecho en la base, con el manubrio alargado y estrecho, apenas curvado. 

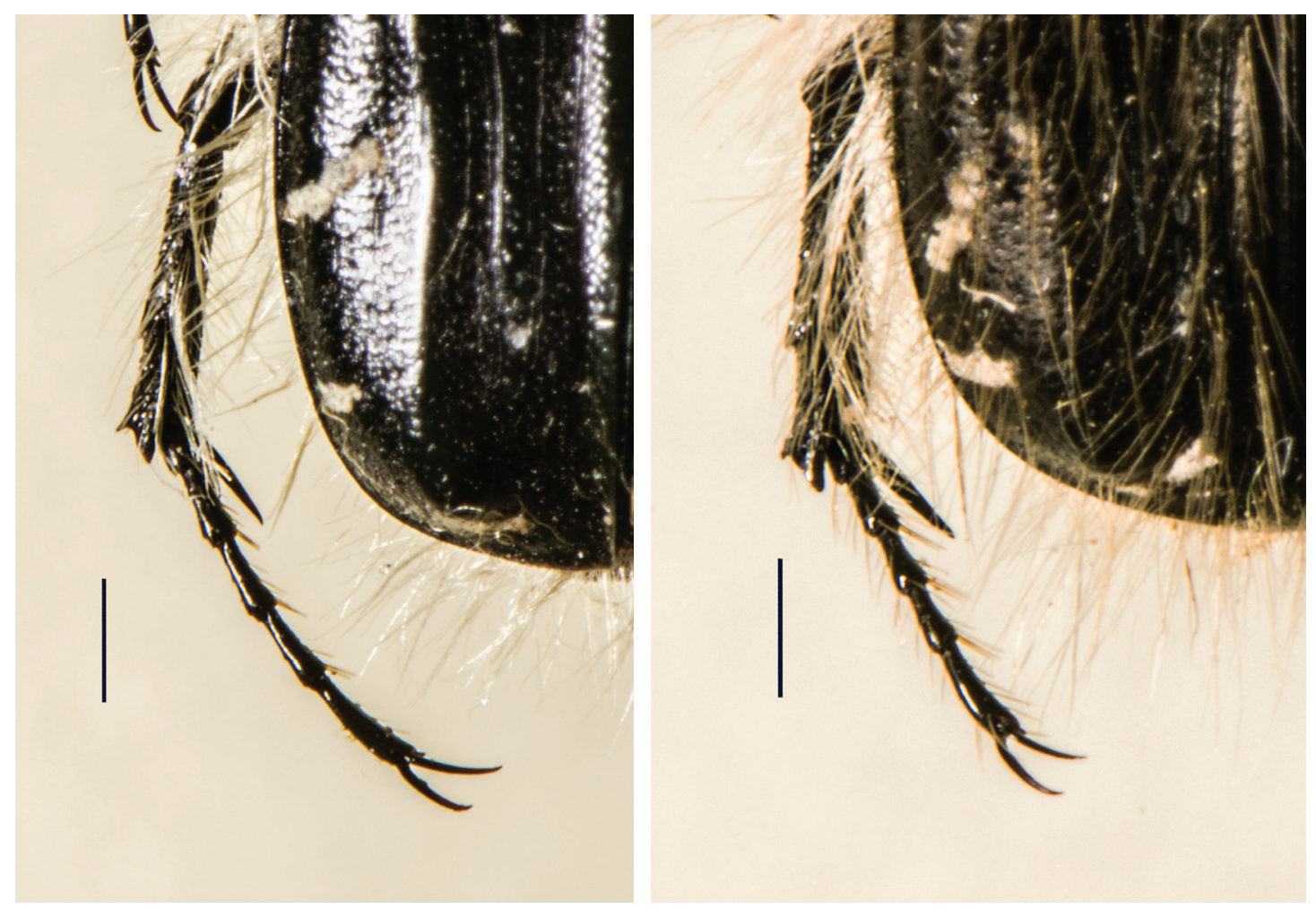

Figs. 7-8.- Pata posterior izquierda, en visión dorsal, de: 7) Tropinota iec sp. n. (Holotipo, Beni Aros, Marruecos); 8) Tropinota hirta (Poda von Neuhaus, 1761) (Mte. di Frassani, Pianello, Italia). Escala: 1 mm. (Fotografías: S. Yubero).

Figs. 7-8.- Left rear leg, dorsal view, of: 7) Tropinota iec sp. n. (Holotype, Beni Aros, Morocco); 8) Tropinota hirta (Poda von Neuhaus, 1761) (Mte. di Frassani, Pianello, Italy). Scale: $1 \mathrm{~mm}$. (Photos: S. Yubero).

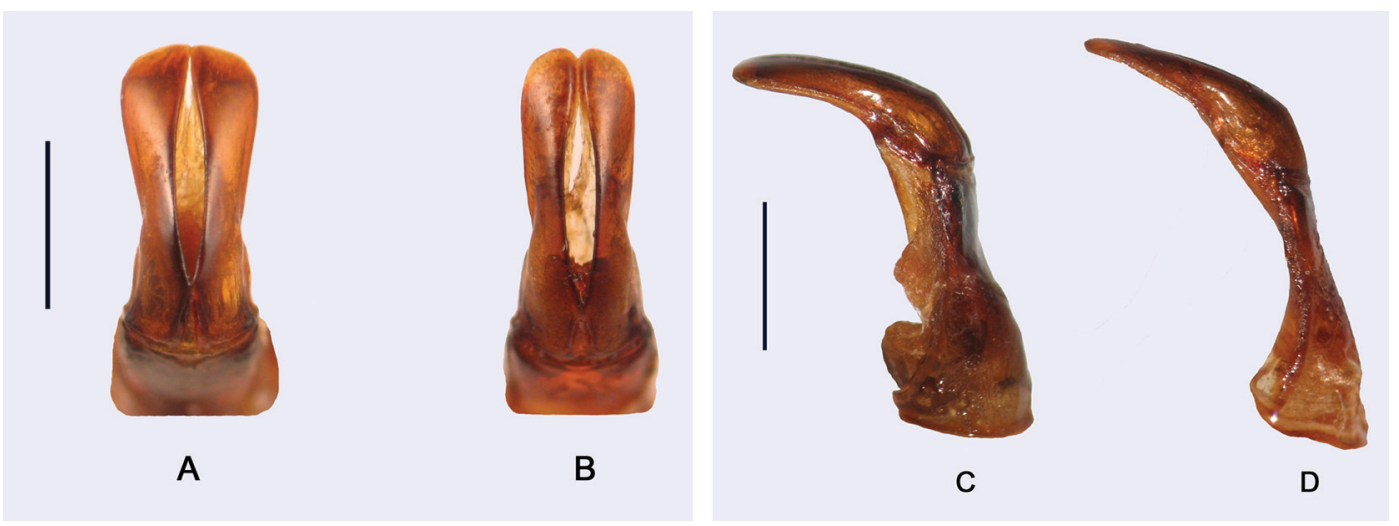

Fig. 9.- Parámeros, en vision dorsal, y tegmen en visión lateral, de: A-C) Tropinota iec sp. n. (Holotipo, Beni Aros, Marruecos); B-D) Tropinota hirta (Poda von Neuhaus, 1761) (Selva de Oza, Huesca, España). Escala: 1 mm. (Fotografías: J.L. Ruiz).

Fig. 9.- Paramera, dorsal view, and tegmen, lateral view, of: A-C) Tropinota iec sp. n. (Holotype, Beni Aros, Morocco); B-D) Tropinota hirta (Poda von Neuhaus, 1761) (Selva de Oza, Huesca, Spain). Scale: 1 mm. (Photos: J.L. Ruiz).

Hembra: Similar al macho, del que se diferencia por escasos caracteres morfológicos externos, que se indican a continuación: aspecto general del cuerpo de la hembra comparativamente un poco más corto aunque menos robusto, con "i.f.a." entre 1.17-1.29, media: $1.22(\mathrm{n}=3)$; maza antenal ligeramente más pequeña que en el macho, de forma que la relación "longitud escapo+funículo/longitud de la maza" en la hembra oscila entre 1.2-1.32, media=1.27 $(\mathrm{n}=3)$ y en el macho entre 1.08-1.16, media= $1.13(\mathrm{n}=4)$; abdomen regularmente convexo en la hembra, algo más globoso, sin presentar la difusa concavidad longitudinal mediana del macho; tercera interestría elitral visiblemente elevada en su tercio basal y quinta interestría un poco elevada en su mitad distal en la hembra, las cuales en el macho apenas sobresalen; las tres hembras estudiadas (incluso en las muy rozadas) presentan las manchas blancas elitrales 
de mayor tamaño y más conspicuas que en los machos, observándose en aquellas una séptima mancha blanca puntiforme, pero visible, en la base de la quinta interestría, a nivel de la región humeral, ausente en los machos examinados. Dos de los tres ejemplares hembra estudiados presentan un fuerte desgaste tegumentario, habiendo perdido la mayor parte de la pilosidad dorsal, sin embargo, un tercer ejemplar (Beni Aros) no muestra desgaste alguno y presenta una abundante pilosidad erecta en el pronoto y élitros, en éstos últimos menos densa (siguiendo el patrón de punteado en el que se inserta); así, la hembra ostenta una pilosidad marcadamente más densa que el macho, sobre todo en los élitros, ya que los machos examinados presentan escasos pelos elitrales incluso en ejemplares sin apenas desgaste tegumentario (holotipo y un paratipo).

VARIABILIDAD: Además de los rasgos indicados para la hembra, la variabilidad detectada es relativamente escasa y afecta de manera perceptible a los siguientes caracteres: longitud total, entre 11.4-12.4 mm, media $=11.95 \mathrm{~mm}, \mathrm{n}=7$ (ठへ 11.4-12.4 mm, media $=11.97 \mathrm{~mm}, \mathrm{n}=4$; 우: 11.7-12.1 mm, media $=11.93 \mathrm{~mm}, \mathrm{n}=3$ ); anchura máxima, situada en todos los ejemplares a nivel de la región humeral de los élitros: $5.85-6.5 \mathrm{~mm}$,

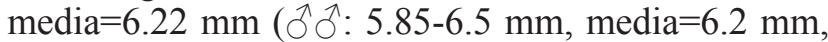
$\mathrm{n}=4$; 우우 $6.2-6.3 \mathrm{~mm}$, media $=6.23 \mathrm{~mm}, \mathrm{n}=3$ ); índice formal absoluto "i.f.a.": 1.17-1.33, media $=1.26, \mathrm{n}=7$ ( $\partial^{\lambda}: 1.26-1.33$, media=1.28, $\mathrm{n}=4$; 우: $1.17-1.29$, media $=1.22, \mathrm{n}=3$ ); longitud del pronoto en la línea media: $3.3-3.45 \mathrm{~mm}$, media $=3.34 \mathrm{~mm}, \mathrm{n}=7$ (ふึ่: $3.25-3.45 \mathrm{~mm}$, media $=3.36 \mathrm{~mm}, \mathrm{n}=4$; 우우: 3.25-3.4 mm, media=3.31 mm, $\mathrm{n}=3$ ); anchura máxima del pronoto: $4-4.5 \mathrm{~mm}$, media $=4.29 \mathrm{~mm}, \mathrm{n}=7$ (ふえ 5.85-6.5 mm, media $=6.2 \mathrm{~mm}, \mathrm{n}=4$; 우 $ᄋ$ : $6.2-6.3 \mathrm{~mm}$, media $=6.23 \mathrm{~mm}, \mathrm{n}=3$ ); relación "longitud metatarsos/longitud metatibias": $1.14-1.22$, media $=1.18, n=7$

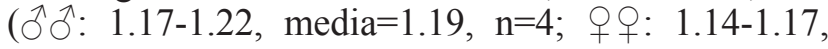
media $=1.15, \mathrm{n}=3$ ); punteado del pronoto, escutelo y élitros, con leves diferencias en su densidad; pilosidad de pronoto y élitros con variación en su densidad, aunque este carácter está estrechamente ligado al grado de desgaste tegumentario, si bien en los cuatro machos estudiados la pilosidad elitral es escasa o muy escasa incluso en dos ejemplares apenas rozados; manchas blancas de los élitros, estrechas y poco conspicuas en los machos, con ligera variabilidad en su amplitud, llegando a desaparecer en un macho la pequeña mancha puntiforme anterior externa, en las hembras las manchas son de mayor tamaño; escasas variación en el punteado de la placa metasternal y de los esternitos abdominales. Por último, la genitalia masculina es bastante uniforme, con escasas diferencias en el ensanchamiento de la región distal de los parámeros, pero en todo caso netamente ensanchados; la relación "longitud falobase/longitud parámeros" (en medición lateral) varía entre 1.04-1.06, media $=1.05(\mathrm{n}=4)$.
DisTRIBUCIÓN Y NOTAS AUTOECOLÓGICAS: Hasta el momento, $T$. iec se conoce únicamente de tres localidades (Fig. 10), que se integrarían en dos núcleos poblacionales relativamente cercanos entre sí (distanciados $30 \mathrm{~km}$ en línea recta), ambos en la región montañosa de la Yebala, Rif occidental, noroeste de Marruecos (región administrativa de Tánger-Tetuán): (1) núcleo poblacional de las montañas de Mulay Abdeselam, en la zona noreste del Parque Regional de Bou-Hachem (extremo noreste de la provincia de Larache); (2) núcleo poblacional de la cuenca del Oued Laou (=río Laou), con dos localidades muy próximas $(8 \mathrm{~km})$, en la zona noreste del Parque Nacional de Talassemtane, ambas en la provincia de Tetuán (en el límite con la provincia de Chefchaouen); una de ellas, Ifahsa, en la garganta del Laou y otra, Beni Ferten, al noreste de la anterior, en el paraje donde concluye la garganta del río y se inicia la llanura de inundación del mismo. La especie se encuentra a baja altitud, con un rango altitudinal estrecho, entre $37-513 \mathrm{~m}$, en áreas de fisionomía montañosa. Estas tres localidades se ubican en el ámbito de afección de la Reserva de la Biosfera Intercontinental del Mediterráneo Andalucía (España)-Marruecos (véase Molina Vázquez, 2006).

La localidad de Mulay Abdeselam (Bou-Hachem) presenta litología de areniscas (flysch de Beni-Ider) que conforman sustratos ácidos, con un ombrotipo húmedo-hiperhúmedo, en el piso bioclimático termomediterráneo (Benabid, 1982, 1984, 1985; Benabid \& Fennane, 1994; Dagnino, 2007). La vegetación potencial y dominante en la actualidad en estas montañas, a baja altitud, está constituida por densos y bien estructurados bosques de alcornocal-quejigal (especies arbóreas dominantes: Quercus suber L. y Quercus canariensis Willd.), con abundante sotobosque, entre otras especies, de Arbutus unedo L., Erica arborea L., Myrtus communis L., Viburbum tinus L., Calluna vulgaris (L.) Hull, Ruscus hypophyllum L., Pteridium aquilinum (L.) Kuhn y Cistus salviifolius L.; estos bosques tingitanos alternan con áreas deforestadas, más o menos amplias, utilizadas para explotaciones agrícolas tradicionales (principalmente cerealísticas y olivares), dando lugar en las zonas bajas-medias a paisajes en mosaico (véase Benabid, 1984; Taiqui, 1997; Taiqui \& Martín Cantarino, 1997; Charco, 1999; Taiqui et al., 2008). El paraje donde se hallaron los tres individuos se corresponde con una zona aclarada en un alcornocal-quejigal, junto a la carretera, con elevada cobertura arbustiva, fundamentalmente de Arbutus unedo, Erica arborea y Cistus salviifolius, en las inmediaciones de un arroyo.

El núcleo poblacional de la cuenca del Oued Laou se asienta sobre materiales calcáreos (dominio de la Dorsal Caliza Rifeña), en una comarca de orografía muy abrupta, en el piso bioclimático termomediterráneo, con ombroclima entre subhúmedo y seco, estando constituida la vegetación dominante por formaciones arbustivas o semiboscosas de araar, Tetraclinis 


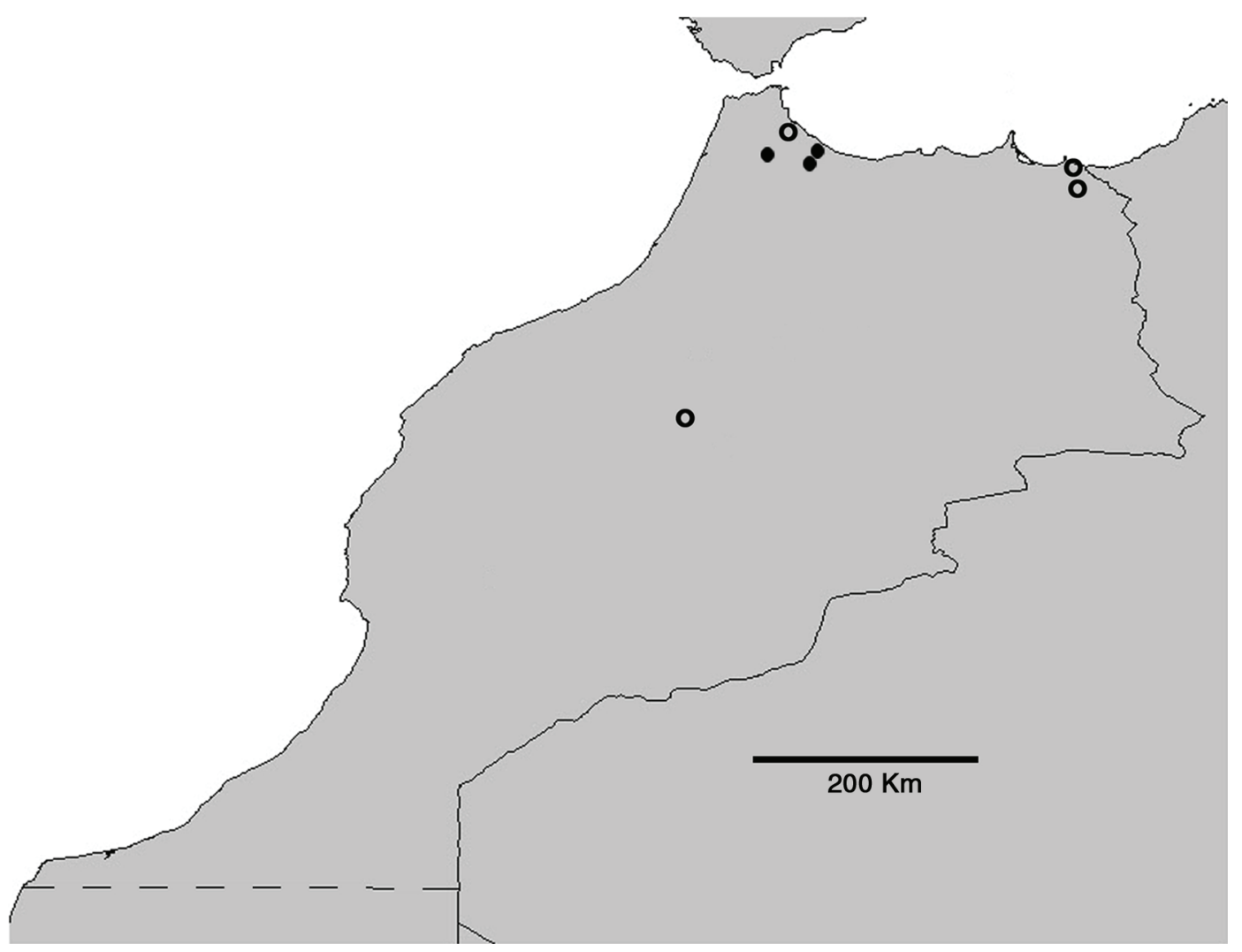

Fig. 10.- Mapa de Marruecos con las localidades conocidas de Tropinota iec sp. n. (círculos negros) y los registros bibliográficos de Tropinota hirta (Poda von Neuhaus, 1761) (círculos vacios).

Fig. 10.- Map of Morocco showing the known locations of Tropinota iec sp. n. (black circles) and bibliographic records of Tropinota hirta (Poda von Neuhaus, 1761) (empty circles).

articulata (Vahl) Masters, con abundante sotobosque y matorral de Pistacia lentiscus L., Calicotome intermedia C. Presl, Chamaerops humilis L., Quercus coccifera L., Olea europea L., Cistus albidus L., y Phlomis purpurea L. ssp. caballeroi (Pau) Rivas Mart. (véase Benabid, 1982, 1984, 2000; Quézel et al., 1988; Benabid \& Fennane, 1994; Charco, 1999; Cassar et al., 2008).

Los ejemplares del Parque Regional de BouHachem se encontraron alimentándose en flores de Cistus salviifolius (Cistaceae) y los de la cuenca del Oued Laou (Ifahsa, Beni Ferten) en flores de Diplotaxis sp. (Brassicaceae). En las tres localidades señaladas se encontraron en microsimpatría con Tropinota (Tropinota) squalida, aparentemente mucho más abundante que la nueva especie, incluso se hallaron juntas en los mismos pies de planta. Los únicos datos fenológicos de los adultos se refieren al mes de mayo, en el que se concentran las capturas; no obstante, los individuos del tramo bajo del Oued Laou, colectados el 26-V-2013, presentaban un fuerte desgaste tegumentario por lo que la aparición de estos adultos debió acaecer bastante antes, posiblemente a finales de abril-principios de mayo.

Etimología: Se dedica esta nueva especie al Instituto de Estudios Ceutíes, en siglas IEC, patronato de la Ciudad Autónoma de Ceuta, en reconocimiento a la encomiable labor que viene desarrollando en pro del conocimiento, investigación y difusión de múltiples aspectos de la región de Ceuta (sociológicos, históricos, económicos, artísticos, científicos, etc.). De hecho, parte del material que compone la serie-tipo fue hallado durante varias excursiones realizadas en el marco de las "Jornadas sobre el Medio Natural de Ceuta y su entorno", actividad plurianual promovida y organizada por dicha institución. El acrónimo "iec" se utiliza como sustantivo en aposición y, por tanto, es invariable.

\section{Discusión}

CARACTERIZACIÓN TAXONÓMICA DE TROPINOTA IEC $\mathbf{s p .} \mathbf{n}$. Y DISCRIMINACIÓN MORFOLÓGICA

Tropinota iec se integra en el grupo de especies o subgénero Epicometis, pues además de ser morfológicamente afín a $T$. hirta [=Scarabaeus hirtellus Linnaeus, 1767, especie-tipo del subgénero; véase Branco (2007)], comparte los principales rasgos que lo definen (e.g. Reitter, 1913; Medvedev, 1964; Crovetti, 1970; Baraud, 1977, 1984, 1985, 1992; Miksic, 1982; Paulian \& Baraud, 1982; Dutto, 2007; véase igualmente Crovetti, 1973: 332, nota 4, para una discusión detallada sobre la variabilidad y validez de los 
caracteres diagnósticos de los subgéneros): pronoto sin áreas lisas de límites irregulares a ambos lados de la carena longitudinal media y $5^{\mathrm{a}}$ interestría elitral generalmente no elevada a modo de costilla ni netamente bifurcada en la base (este rasgo, no obstante, no es común a la totalidad de las especies adscritas al subgénero, presentando varias excepciones); sin embargo, el abdomen del macho es levemente cóncavo en la región media ventral, a diferencia de T. hirta y el resto de especies de Epicometis, que presentan el abdomen regularmente convexo en el macho.

En el mediterráneo occidental, Epicometis únicamente cuenta con tres especies: T. (E.) hirta hirta, de amplia distribución europea-mediterránea (e.g. Baraud, 1977, 1992; Paulian \& Baraud, 1982; Krajcik, 1998; Bunalski, 1999; Dutto, 2005; Micó \& Galante, 2002; Smetana, 2006; Blanco Villero, 2010), citada en el norte de África de tan sólo cuatro localidades de Marruecos septentrional (Baraud, 1985; Chavanon, 2002); T. (E.) annabrunae, sólo conocida de la localidad-tipo, Tagiura, en la costa mediterránea occidental de Libia, al este de Trípoli (Crovetti, 1973, 1974; Baraud, 1984, 1985; Dutto, 2007); y la recientemente descrita T. (E.) paulae, exclusiva de la isla de Cerdeña (Leo, 2010; Carpaneto et al., 2011).

Tropinota annabrunae se segrega claramente de T. iec, por los siguientes caracteres: la primera de ellas presenta la $5^{\mathrm{a}}$ interestría elitral manifiestamente elevada y lisa ("costilla externa", según Crovetti, 1973), sobre todo en la mitad anterior, y bifurcada y fuertemente elevada en la base a nivel del callo humeral [véase Crovetti, 1973: 340, fig. 13, 342, a diferencia de lo señalado por Baraud (1985: 590) que erróneamente indica en su clave (sic): "Cinquième interstrie élytral non relevé en côte ni bifurqué en avant"] y la $3^{a}$ interestría igualmente elevada, subcostiforme en la base ("costilla mediana" según Crovetti, 1973), mientras que en $T$. iec ambas interestrías no ofrecen aspecto subcostiforme y apenas están elevadas; élitros desprovistos de las estrías longitudinales manifiestas en T. annabrunae (rasgo que, según Crovetti, 1973: 342 , es por sí solo diagnóstico de la especie), las cuales están presentes en $T$. iec; escutelo con fuertes y profundas interestrías laterales y punteado restringido a la base en $T$. annabrunae, siendo en $T$. iec dichas depresiones escutelares menos amplias y el punteado se distribuye tanto por la base como por los márgenes; esternitos abdominales del macho regularmente convexos en la primera, con una débil y difusa depresión longitudinal media en la segunda; por último, la genitalia masculina es muy distinta, con los parámeros, en visión dorsal, de lados subparalelos y estrechos en T. annabrunae (ver Crovetti, 1973: 337, fig. 8; Baraud, 1985: 592, fig. 203b), ampliamente ensanchados y de aspecto espatulado en T. iec (Fig. 9).

De $T$. paulae se diferencia, entre otros rasgos, por presentar ésta un aspecto más ancho y robusto, con "i.f.a." comprendido entre 1.01-1.12, la $3^{\mathrm{a}}$ interestría elitral netamente elevada, sobre todo en la zona central, subcostiforme ("costilla media" según Leo, 2010) y la $5^{\text {a }}$ igualmente subelevada, siendo ambas no o muy escasamente elevadas en T. iec; el escutelo muestra acanaladuras laterales más anchas y marcadas y el punteado restringido a la base en la primera; las manchas blancas de los élitros más anchas y conspicuas (aunque este carácter está sujeto a amplia variabilidad individual y poblacional en la mayor parte de las especies del género); los esternitos abdominales son regularmente convexos en ambos sexos, sin surco longitudinal mediano en T. paulae; y el edeago es muy distinto, con los parámeros no dilatados apicalmente, de lados subparalelos en visión dorsal (Leo, 2010: 6-7, figs. 3, 4).

La especie más cercana morfológicamente a $T$. iec es $T$. hirta, representada en el mediterráneo occidental por la subespecie T. hirta hirta. Ambas se separan por la conjunción de los siguientes caracteres: aspecto general del cuerpo un poco más robusto y ancho en T. iec, con "i.f.a." entre 1.17-1.33, media=1.26 $(\mathrm{n}=7)$, variando en $T$. hirta entre $1.17-1.44$, media $=1.29$ $(n=20)$; tegumento corporal, sobre todo patente en el pronoto y élitros, de aspecto semimate, con microrreticulado manifiesto en $T$. hirta, siendo netamente brillante y con microrreticulado muy suave en T. iec (Figs. 1-4); pilosidad corporal, sobre todo en el pronoto y élitros, manifiestamente más densa y con pelos más gruesos y erectos, generalmente amarillentos, en T. hirta (si bien este carácter es muy variable a nivel inter- e intrapoblacional, y la densidad de la pilosidad está igualmente ligada al desgaste tegumentario individual), mientras que en $T$. iec la pilosidad es blanquecina, con pelos más finos y débiles, fácilmente caedizos y semirrizados (en la región dorsal), mucho menos densos, sobre todo en los machos, incluso en los ejemplares que apenas presentan desgaste tegumentario; manchas blancas de los élitros en general más reducidas en número y tamaño en $T$. iec, en la que aparecen un máximo de 5-6 en machos y 6-7 en hembras, y en $T$. hirta un total de 7 (más o menos amplias), tanto en machos como hembras; punteado del pronoto con puntos más gruesos y espaciados en $T$. iec, netamente más finos y densos en T. hirta (Figs. 5-6); punteado elitral significativamente más denso en todas las interestrías en T. iec, con las marcadas diferencias que se detallan en el Apéndice 2; tarsos de todas las patas más largos y estilizados en T. iec, con los artejos tarsales mas estrechos y alargados (Figs. 7-8), de manera que la relación "longitud metatarsos/longitud metatibias" en $T$. iec oscila entre 1.14-1.22 (media=1.18, $\mathrm{n}=7$ ) y en T. hirta entre 0.84-1 (media $=0.91, \mathrm{n}=20$ ); placa mesosternal en T. hirta con punteado muy fuerte y denso, con puntos confluentes o subconfluentes incluso en la región central, con una separación entre ellos menor a su diámetro, siendo en T. iec mucho menos denso e impreso, especialmente en la región central, donde se observan zonas lisas, con separación entre los puntos normalmente entre 1.5 y 3 veces su diámetro. Por último, el edeago es 
diferente en ambas especies (Fig. 9): parámeros estrechos, de lados subparalelos y no o muy escasamente ensanchados hacia los lados en el tercio apical en visión dorsal en $T$. hirta, mientras que en $T$. iec los parámeros son netamente ensanchados desde el medio hacia el extremo, de aspecto espatulados, con la mayor anchura en la región apical; asimismo, en visión lateral muestran un aspecto más robusto en T. iec.

La subespecie oriental T. hirta suturalis Reitter, 1913, descrita como especie independiente (Reitter, 1913), y subordinada a subespecie de T. hirta por Petrovitz (1971), donde es mantenida posteriormente por la mayor parte de autores (e.g. Miksic, 1982; Baraud, 1984; Krajcik, 1998; Smetana, 2006; aunque Baraud, 1992 señala que en las poblaciones de Europa sudoriental se encuentra mezclada con la subespecie nominal, por lo que podría considerarse una mera forma de $T$. hirta), presenta los parámeros del edeago un poco más cortos y anchos en visión dorsal que la subespecie nominal, si bien sus lados externos son subparalelos (Medvedev, 1964: 103, figs. 160-161; Baraud, 1984: 63, fig. 3; Sabatinelli, 2008), y en todo caso sin el neto ensanchamiento en la mitad distal de los parámeros que caracteriza a T. iec. Tropinota hirta suturalis presenta, al igual que T. iec, el tegumento corporal brillante, pero se separa bien de esta por la morfología de los parámeros, además de por el resto de caracteres señalados para la subespecie nominal; asimismo, $T$. $h$. suturalis muestra las manchas blancas elitrales manifiestamente más anchas y transversas y un "i.f.a." mayor, de media 1.36 y rango entre 1.28-1.47 (Dutto, 2007: 87), frente a T.iec, cuyo "i.f.a." medio es 1.26 , variando entre $1.17-1.33$, media $=1.26$ $(\mathrm{n}=7)$. Esta subespecie muestra una extensa distribución por el sudeste de Europa (incluida Ucrania), Cáucaso, Anatolia, y Oriente próximo y medio, entre Croacia al oeste y Afganistán al este (e.g. Medvedev, 1964; Miksic, 1982; Baraud, 1984, 1992; Smetana, 2006; Dutto, 2007; Rozner \& Rozner, 2009; Tauzin \& Rittner, 2012), existiendo una amplia discontinuidad geográfica respecto a $T$. iec, de un mínimo de $2.400 \mathrm{~km}$.

T. hirta crispa Petrovitz, 1971, subespecie semidesconocida sólo registrada de la localidad-tipo, Menemem-Vilayet Izmir, Turquía (Petrovitz, 1971), simpátrica con $T$. hirta suturalis, se diferencia de T. hirta hirta por muy escasos caracteres expuestos en la descripción original, muy variables en el género y que podrían ser propios de variabilidad interpoblacional, como un tamaño mayor $(15.5 \mathrm{~mm})$, aspecto más ancho y plano, y pequeñas diferencias en la densidad de la pilosidad pronotal y elitral. Esta supuesta subespecie (ignorada por algunos autores, como Baraud, 1977, 1992) se diferenciaría de T. iec por los mismos caracteres indicados para la subespecie nominal. Por otra parte, T. hirta hirtiformis Reitter, 1913, descrita como especie independiente (Reitter, 1913), considerada como tal por diversos autores (e.g. Medvedev, 1964;
Baraud, 1984; Carpaneto et al., 2000; Dutto, 2007; Sabatinelli, 2008) y por Miksic (1982) como subespecie de T. hirta (criterio seguido por Krajcik, 1998 y Smetana, 2006), se segrega morfológicamente de T.iec por mostrar aquella los lados del pronoto con un reborde liso, bien visible en toda su longitud y ensanchado en la región anterior y el escutelo punteado sólo en la base, mientras que en la segunda el reborde pronotal es muy fino, sólo visible en la zona anterior e interrumpido por el punteado, y el escutelo punteado en la base y lados; asimismo, los parámeros de esta subespecie no son ensanchados en la región distal, con sus lados externos subparalelos (Medvedev, 1964; Miksic, 1982; Baraud, 1984). Al igual que T. h. suturalis, el área de distribución $T$. $h$. hirtiformis es oriental (véase Baraud, 1984; Smetana, 2006; Sabatinelli, 2008), con una separación geográfica respecto a T. iec mayor de $4.000 \mathrm{~km}$.

El resto de especies del subgénero Epicometis mediterráneo-orientales y/o turánicas, $T$. (E.) turanica Reitter, 1889, T. (E.) spinifrons Reitter, 1889, T. (E.) senicula (Ménétriés, 1832) y T. (E.) villiersi Baraud, 1984, se diferencian claramente de T. (.E.) iec por presentar aquellas los parámeros con los lados externos subparalelos, no o apenas ensanchados en su mitad distal (véase Medvedev, 1964; Baraud, 1984), además de otros rasgos de la morfología externa característicos de cada una de ellas (pueden consultarse e.g. en Medvedev, 1964; Miksic, 1982; Baraud, 1984, 1992; Sabatinelli, 2008; Tauzin \& Rittner, 2012).

Por otro lado, la recientemente descrita $T$. (E.) ilariae conocida únicamente de tres localidades y otros tantos ejemplares, procedentes de Israel [loc. typ.: "Tiberias, Lower Galilee, 150 m" (Dutto, 2007) y Hebron (Rittner, 2009)] y Jordania [Amman (Sabatinelli, 2008)] presenta los parámeros ampliamente ensanchados y redondeados en la región apical; no obstante, se diferencia claramente de T. iec por mostrar aquella la zona apical de los parámeros más dilatada y sinuada en los lados externos, y los márgenes internos de los parámeros tangentes en toda su longitud, sin dejar apenas espacio entre ellos (Dutto, 2007: 89, fig. 2), siendo en T. iec dichos márgenes internos ampliamente arqueados, conformando un espacio libre entre ellos de aspecto fusiforme en visión dorsal. La morfología externa de ambas es muy diferente: T. ilariae es significativamente más estrecha y estilizada, sobre todo a nivel de los élitros, con "i.f.a."=1.95 (Dutto, 2007), mientras que en T. iec varía entre $1.17-1.33$, media $=1.26(\mathrm{n}=7)$; asimismo, la pilosidad es mucho más densa y larga, con el abdomen fuertemente cóncavo y la espina distal interna de las protibias alargada y netamente curvada en el ápice en la primera (Dutto, 2007; Sabatinelli, 2008; véanse fotografías de G. Sabatinelli en Rittner, 2009; Tauzin \& Rittner, 2012). Como indica Dutto (2007), $T$. (E.) ilariae es inconfundible con otras especies del género. 
Por último, las otras dos especies norteafricanas del género Tropinota, adscritas a subgéneros distintos, T. (Tropinota) squalida (Scopoli, 1763) y T. (Hemiopta) bleusei (Bedel, 1896), son bien distintas de la nueva especie. Así, la primera, representada en todo el norte de África por la subespecie T. (T.) squalida pilosa (Brullé, 1832), ampliamente distribuida además por Oriente próximo y sureste de Europa, se separa de $T$. iec, entre otros muchos caracteres, por presentar aquella la $5^{a}$ interestría elitral fuertemente elevada, costiforme y bifurcada en $\mathrm{V}$ en la región humeral, el escutelo sólo punteado en la base, la pilosidad corporal más densa y los parámeros de lados externos rectos y fuertemente incurvados en el ápice (e.g. Baraud, 1977, 1985, 1992; Paulian \& Baraud, 1982). En cuanto a T. (H.) bleusei, conocida exclusivamente del suroeste de Argelia en hábitats áridos saharianos (Bedel, 1896; Reymond, 1954; Baraud, 1985), se segrega de la nueva especie por presentar aquella los siguientes rasgos: margen anterior del clípeo débilmente sinuado en medio, con los ángulos laterales apenas denticulados; pilosidad corporal muy larga y densa; pronoto con punteado muy fino y denso; élitros rojizos en los laterales y región apical; $5^{\mathrm{a}}$ interestría netamente elevada y parámeros del edeago de lados rectos, subparalelos, nada ensanchados en el ápice (e.g. Bedel, 1896; Reitter, 1913; Dahlgren, 1972; Baraud, 1985).

Sobre la PRESEnCia de TROPINOTA HIRTA En MarRuecos: POSIBLE CONFUSIÓN CON TROPINOTA IEC SP. N.

Tropinota hirta no fue detectada en el norte de África hasta que Baraud (1985) la registró, en base a muy escaso material (conservado en el Muséum National d'Historie Naturelle, París, Francia), de dos localidades del norte y centro de Marruecos: Tetuán (=Tetouan; $\left.35^{\circ} 34^{\prime} \mathrm{N} 5^{\circ} 22^{\prime} \mathrm{O}, 10-190 \mathrm{~m}\right)$ en el noreste de la Península Tingitana, a partir de una hembra (IV-1907, Vaucher leg.), y de Kasba-Tadla $\left(32^{\circ} 36^{\prime} \mathrm{N} 6^{\circ} 15^{\prime} \mathrm{O}, 505 \mathrm{~m}\right)$, en las estribaciones suroccidentales del Medio Atlas, sobre 3 ejemplares sin especificar sexo (IV-1926, Antoine leg.), y comenta que si bien esta segunda localidad resulta extraña para la especie, su verosimilitud vendría avalada por la autoridad de su colector. Este autor no efectuó comentarios sobre particularidades morfológicas de estos especímenes ni sobre variabilidad respecto a poblaciones europeas de T. hirta. Chavanon (2002) mencionó, con dudas, la presencia de la especie en Marruecos nororiental, en concreto en Taforalt, macizo de Beni Snassen $\left(34^{\circ} 48^{\prime} \mathrm{N} 2^{\circ} 24^{\prime} \mathrm{O}, 820 \mathrm{~m}\right)$ y en la Desembocadura del río Muluya (=Oued Moulouya, $35^{\circ} 07^{\prime} \mathrm{N} 2^{\circ} 20^{\prime} \mathrm{O}, 0-3 \mathrm{~m}$ ), comentando para ambas localidades (sic): "Très rare au Maroc et localité très excentrée. Présence de l'espèce à confirmer".

Por tanto, la presencia de esta especie en Marruecos se fundamenta en tan solo cuatro registros (Fig. 10), dos de ellos basados en mínimas capturas de hace más de 80 años, y otros tantos necesitados de confirmación según su propio autor. Así, parece evidente la rareza y escasez de las poblaciones de T. hirta en territorio marroquí; apreciación que vendría apoyada por el hecho de que Martínez de la Escalera (1914) y Kocher (1958) no la citaron en sus respectivos catálogos de coleópteros de Marruecos, a pesar de que estos autores muestrearon intensamente en el país y en especial en las regiones donde posteriormente fue citada la especie (Península Tingitana, Medio Atlas).

Aunque no hemos estudiado el material sobre el que Baraud (1985) basó sus registros, es muy probable que estos ejemplares fuesen asignables a $T$. iec en lugar de a T. hirta, habida cuenta que las diferencias morfológicas son poco llamativas a primera vista (sobre todo en las hembras) y su ponderación requiere de un examen comparado entre ambas, así como el estudio de la genitalia masculina. Además, las localidades conocidas de T. iec son relativamente cercanas a Tetuán, de donde se citó a T. hirta. En caso de confirmarse esta hipótesis, en el norte de Marruecos sólo habitaría una especie de Tropinota del subgénero Epicometis, T. (E.) $i e c$, que podría haber sido confundida previamente con T. hirta.

Por otra parte, $T$. iec vive en microsimpatría con T. squalida pilosa $\mathrm{y}$, en efecto, hemos observado simultáneamente a ambas especies en las tres localidades conocidas, incluso alimentándose en flores de los mismos pies de planta, siendo la segunda mucho más abundante que la primera. Este hecho, unido al carácter de especie frecuente y abundante de T. squalida pilosa, ha podido contribuir a enmascarar la presencia de T. iec (o de las supuestas poblaciones de T. hirta) en Marruecos. A raíz de estas consideraciones, como propuesta de trabajo futura, estimamos de interés: (1) efectuar una revisión crítica de los ejemplares de Tropinota marroquíes integrados en colecciones, inclusive la totalidad de las series identificadas como T. squalida; (2) realización de muestreos específicos, sobre todo en zonas con fisionomía montañosa de la mitad norte de Marruecos, dirigidos a la localización de esta nueva especie, lo que en la práctica supone el examen detallado en el campo de un elevado número de individuos de Tropinota por localidad.

Con todo, y a pesar de eventuales confusiones con las otras dos especies del género señaladas de Marruecos, una de presencia dudosa (T. hirta) y otra abundante y de amplia distribución en el país ( $T$. squalida), realmente T. iec debe ser una especie con núcleos poblacionales dispersos, más o menos aislados y con efectivos aparentemente escasos, como nos sugiere su ausencia o rareza en colecciones (en caso de pertenecer a esta especie los ejemplares estudiados por Baraud, 1985), el hecho de no haber sido descubierta hasta la fecha $y$, por último, nuestras propias observaciones de campo. Una tendencia similar se observa respecto a $T$. hirta en la mitad sur de la Península Ibérica, en donde parecen rarificarse y fragmentarse 
sus poblaciones a medida que disminuye la latitud, contrariamente a lo que ocurre con T. squalida, abundantísima y muy frecuente en el sur ibérico (Micó \& Galante, 2002; Branco, 2005; Blanco Villero, 2010).

\section{Agradecimientos}

A Saúl Yubero, por la realización de las fotografías que ilustran este trabajo y su entusiasta colaboración. A Mario García-París por la lectura crítica del manuscrito y apoyo en todo momento. A Mercedes París, que nos facilitó el estudio del valioso material de la colección del MNCN y a José Ramón Verdú (CIBIO), que hizo otro tanto con ejemplares de la colección entomológica de la Universidad de Alicante (CEUA). A los siguientes colegas, por la cesión y/o préstamo de material de comparación, sin cuyo concurso no hubiera sido posible esta contribución: Pablo Bercedo, Lucía Arnáiz, Giuseppe Carpaneto, Jorge M. Lobo, Stefano Ziani y Julio Ferrer. Por último, a Manuel Cámara, Simón Chamorro, Ricardo Ugarte, Fco. Javier Martínez y Álvaro Velasco, todos ellos miembros del IEC, con los que compartimos inolvidables jornadas de campo por la Yebala, Gomara y Rif.

\section{Referencias}

Arrow, G. J., 1910. The Fauna of British India, including Ceylon and Burna. Coleoptera Lamellicornia (Cetoniinae and Dynastinae). Taylor \& Francis. London. xiv+322 pp., 2 láms.

Báguena, L., 1967. Los Scarabaeoidea de la fauna iberobalear y pirenaica. Instituto Español de Entomología, CSIC. Madrid. 575 pp.

Baraud, J., 1977. Coléoptères Scarabaeoidea. Faune de 1'Europe occidental: Belgique, France, GrandeBretagne, Italie, Péninsule Ibérique. Nouvelle Revue d'Entomologie, 7, suppl. I: 1-352.

Baraud, J., 1984. Tropinota (Epicometis) villiersi nouvelle espèce du Moyent-Orient (Coleoptera, Scarabaeoidea, Cetoniidae). Revue Française d'Entomologie (N.S.), 6(2): 61-63.

Baraud, J., 1985. Coléoptères Scarabaeoidea. Faune du nord de l'Afrique, du Maroc au Sinaï. Lechevalier. Paris. $650 \mathrm{pp}$.

Baraud, J., 1992. Coléoptères Scarabaeoidea d'Europe. Série Faune de France 78. France et régions limitrophes. Fédération française des Sociétés de Sciences naturelles et Société linnéenne de Lyon. Lyon. 856 pp.

Bedel, L., 1896. Nouveau type algérien de la tribu des Cetoniini (Col.). Bulletin de la Société Entomologique de France, [1896]: 384-385.

Benabid, A., 1982. Études phytoécologique, biogéographique et dinamique des associations et séries sylvatiques du Rif occidental (Maroc). Thèse Doct. ès-Sc. Faculté des Sciences et Techniques St. Jerôme, Université de Droit, d'Economie et des Sciences d'Aix-Marseille. iii+199 pp.

Benabid, A., 1984. Étude phytoécologique des peuplements forestiers et préforestiers du Rif centro-occidental (Maroc). Travaux de l'Institut Scientifique, Rabat, série Botanique, 34: 1-64, 25 tab., 2 cart.

Benabid, A., 1985. Les écosystèmes forestiers, préforestiers et presteppiques du Maroc: diversité, répartition biogéographique et problèmes posés par leur aménagement. Forêt méditerranéenne, 7(1): 53-64.

Benabid, A., 2000. Flore et écosystèmes du Maroc. Évaluation et préservation de la biodiversité. Ibis Press. Paris. 359 pp.

Benabid, A. \& Fennane, M., 1994. Connaissances sur la végétation du Maroc: Phytogéographie, phytosociologie et séries de végétation. Lazaroa, 14: 21-97.

Blanco Villero, J. M., 2010. Nuevos datos sobre Tropinota (Epicometis) hirta (Poda, 1761) para Andalucía (Coleoptera: Scarabaeoidea, Cetoniidae) y revisión de su corología ibérica. Boletín de la Asociación española de Entomología, 34(3-4): 423-425.

Branco, T., 2005. Contributions towards a Catalogue of Scarabaeoidea of Portugal (Coleoptera). Elytron, 19: 49-61.

Branco, T., 2007. Scarabaeoidea (Coleoptera) of Portugal: genus-group names and their types species. Zootaxa, 1453: 1-31.

Bunalski, M., 1999. Die Blatthornkäfer Mitteleuropas. Coleoptera, Scarabaeoidea. Bestimmung-VerbreitungÖkologie. Frantisek Slamka. Bratislava. 80 pp.

Carpaneto, G., Piatella, E., Dellacasa, G., Dellacasa, M., Pittino, R. \& Mazziota, A., 2011. The Lamellicornia beteles of southern Sardinia (Coleoptera: Scarabaeoidea). Conservazione Habitat Invertebrati, 5: 353-387.

Carpaneto, G., Piatella, E. \& Pittino, R., 2000. The scarab beetles of Turkey: an update checklist and chorotype analysis (Coleoptera, Scarabaeoidea). Biogeographia, 21: 217-240.

Cassar, L. F., Conrad, E. S., Gati, P., Lafranco, E. \& Rolé, A., 2008. The Thermo-Mediterranean biotopes of the Oued Laou bassin: a landscape approach. In: A: Bayed $\&$ M. Ater (Eds.). Du basin versant vers la mer: Analyse multidisciplinaire pour une gestion durable. Travaux de l'Institut Scientifique, Rabat, série générale, 5: 17-36.

Charco, J., 1999. El bosque mediterráneo en el norte de África. Biodiversidad y lucha contra la desertificación. Agencia Española de Cooperación Internacional. Madrid. 370 pp.

Chavanon, G., 2002. Rapport d'analyse de la faune. Étude sur les invertébrés terrestres des sites concernés par le project: Cap des Trois Fourches, Beni Snassen, Lagune de Nador, Embouchure de la Moulouya, Mont Gourougou. 56 pp. En: MedWetCoast Project. Morocco. Disponible en: http://vinc.s.free.fr/article.php3?id article $=86$ (consultado el 27/03/2014).

Crovetti, A., 1970. Contributi alla conoscenza dei Coleotteri Scarabeidi, II. Il genere Epicometis Burmeister in Sardegna (Coleoptera, Scarabaeoidea, Cetoniinae). Studi Sassaresi, Annali della Facoltà di Agraria dell'Università di Sassari, 18(1): 3-27.

Crovetti, A., 1973. Resultati delle missioni entomologiche dei proff. G. Fiori ed E. Mellini nel Nord-Africa. XXVII. Epicometis (Epicometis) annabrunae n. sp. della Libia. Atti della Società Italiana di Scienze Naturali e del Museo Civico di Storia Naturale di Milano, 114(3): 330-344.

Crovetti, A., 1974. Resultati delle missioni entomologiche dei proff. G. Fiori ed E. Mellini nel Nord-Africa. XXVII. Les Epicometis Burmeister della Libia (Coleoptera, 
Scarabaeidae, Cetoniinae). Studi Sassaresi, Annali della Facoltà di Agraria dell'Università di Sassari, 22: 3-28.

Dagnino, A., 2007. Le Parc naturel régional expérimetal de Bouhachem, Région du Rif, Maroc. Forêt méditerranéenne, 28(1): 59-66.

Dahlgren, G., 1972. Zur Taxonomie der Gattungen Aethiessa, Oxythyrea, Tropinota und Musurgus (Col. Scarabaeidae). Entomologica Scandinavica, 3(2): 161-168.

Dutto, M., 2005. Monografia Entomologiche Vol. I. Coleotteri Cetoniidae d'Italia. Natura Edizioni Scientifiche. Bologna. 215 pp., 17 láms.

Dutto, M., 2007. Tropinota (Epicometis) ilariae, nuova specie di Israele (Coleoptera Scarabaeoidea Cetoniidae). Naturalista siciliano, 31(1-2): 85-90.

Horion, A. D., 1958. Lamellicornia (ScarabaeidaeLucanidae). In: Faunistik der Mitteleuropaischen Käfer, vol. 6. Kommissionsverlag Buchdruckerei aug Feyel. Überlingen Bodensee: 1-57.

Keith, D., 2006. Qu'est-ce que Tropinota (Epicometis) jakesi Balthasar, 1967 (Coleoptera, Scarabaeoidea, Cetoniidae)? Animma. X, 14: 17-18.

Kocher, L., 1958. Catalogue commenté des Coléoptères du Maroc. VII. Lamellicornes. Travaux de l'Institut Scientifique Chérifien (série Zoologie), 16: 1-83.

Krajcik, M., 1998. Cetoniidae of the World, Catalogue-Part I (Coleoptera: Cetoniidae). Typos Studio. Most. 96 pp.

Leo, P., 2010. Una nuova specie di Tropinota della Sardegna (Coleoptera, Scarabaeoidea, Cetoniidae). Doriana, 8(369): 1-13.

Martínez de la Escalera, M., 1914. Los Coleópteros de Marruecos. Trabajos del Museo Nacional de Ciencias Naturales, serie Zoológica, 11: 1-553.

Medvedev, S. I., 1964. Fauna SSSR. Zhestkokrylye. Tom X, vyp. 5 Plastinchatousye (Scarabaeidae), Podsem. Cetoniinae, Valginae. Zoologicheskii Institut, Akademia Nauk SSSR. Moskow \& Leningrad. 376 pp.

Micó, E. \& Galante, E., 2002. Atlas fotográfico de los escarabeidos florícolas ibero-baleares. Argania editio. Barcelona. 80 pp.

Miksic, M., 1982. Monographie der Cetoniinae der paläarktischen und orientalischen Region. Coleoptera Lamellicornia. Band 3. Systematischer Teil: Cetoniini 1. Teil. Sarajevo. 530 pp., 14 pls.

Molina Vázquez, F., (Coord.), 2006. Reserva de la Biosfera Intercontinental del Mediterráneo Andalucía (España)Marruecos. Junta de Andalucía, Consejería de Medio Ambiente. Sevilla. 209 pp.

Paulian, R., 1959. Coléoptères Scarabéides. Faune de France, vol. 63. Lechevalier. Paris. 298 pp.

Paulian, R. \& Baraud, J., 1982. Faune des Coléoptères de France. II. Lucanoidea et Scarabaeoidea. Lechevalier. Paris. 477 pp.

Petrovitz, R., 1971. Ergebnisse zoologischer Sammelreisen in der Türkei, Lamellicornia, Coleoptera. Annalen des Naturhistorischen Museum in Wien, 75: 565-589.
Quézel, P., Barbero, M., Loisel, R. \& Rivas-Martínez, S., 1988. Contribution à l'étude des groupements préforestiers et des matorrals rifains (Maroc). Ecologia Mediterranea, 14: 14-122.

Reitter, E., 1913. Uebersicht der paläarktischen Arten der Coleopterengattung Tropinota Muls. Entomologische Blätter, 9/10: 224-227.

Reymond, A., 1954. Addition à la connaissance entomologique de la faune du Maroc sud-oriental (Missions de l'Institut Scientifique Chérifien d'avril a juillet 1953). Bulletin de la Société des Sciences Naturelles et Physiques du Maroc, 34: 41-53.

Rittner, O., 2009. Tropinota ilariae (Scarabaeidae, Cetoniinae). In: Israel's Nature Site [Web en línea]. Disponible en: http://www.nature-of-oz.com/apps/forums/topics/ show/1710507 (consultado el 9/03/2014).

Rozner, I. \& Rozner, G., 2009. Additional data to the Lamellicornia Fauna of Turkey (Coleoptera: Lamellicornia). Natura Somogyiensis, 15: 69-100.

Sabatinelli, G., 2008. Genus Tropinota Mulsant, 1842. En: The Scarabs of the Levant: Syria, Lebanon, Jordan, Palestine, Israel, Sinai [Web en línea]. Disponible en: http://www.glaphyridae.com/Cetoniinae/Tropinota.html (consultado el 7/03/2014).

Sabatinelli, G., Rittner, O. \& Tauzin, P.-H., 2010. Tropinota vittula Reiche \& Saulcy. 1856 is a good species (Coleoptera, Scarabaeidae, Cetoniinae). Lambillionea, 110(1): 35-42.

Smetana, A., 2006. Cetoniinae. En: I. Löbl \& A. Smetana (Eds.). Catalogue of Palaearctic Coleoptera. Vol. 3. Apollo Books. Stenstrup: 283-313.

Taiqui, L., 1997. La degradation ecologique au Rif marocain: nécessités d'une nouvelle approach. Mediterranea, Serie de estudios biológicos, 16: 5-17.

Taiqui, L., Martín, J. \& Seva, E., 2008. Structure, Diversité et dynamique des súberaies du paysage rural de Chefchaouen. Annales de la recherche forestière du Maroc, 39: 43-57.

Taiqui, L. \& Martín Cantarino, C., 1997. Éléments historiques d'analyse écologiques des paysages montagneux du Rif occidental (Maroc). Mediterranea, Serie de estudios biológicos, 16: 23-35.

Tauzin, P.-H. \& Rittner, O., 2012. Cetoniinae of the Levant: chorological general survey (Coleoptera, Scarabaeidae). Le Coléoptèriste, 15 (Supplément, Sep. 2012): 1-72.

Wiley, E. O., 1978. The evolutionary species concept reconsidered. Systematic Zoology, 27: 17-26. http://dx.doi. org/10.2307/2412809.

Wiley, E. O., 1981. Phylogenetics. The theory and practice of phylogenetic systematics. University of Kansas, Lawrence \& John Wiley and sons, New York. 439 pp. http://dx.doi.org/10.1002/9781118017883.

Wiley, E. O. \& Mayden, R. L., 2000. The evolutionary species concept. In: Q. D. Wheeler \& R. Meier (Eds.). Species Concept and Phylogenetic Theory: A Debate. Columbia University Press. New York: 70-92. 
Apéndice 1.- Material examinado de Tropinota hirta (Poda von Neuhaus, 1761). Las siglas utilizadas son las siguientes: MNCN: Museo Nacional de Ciencias Naturales-CSIC, Madrid (España); CEUA: Colección Entomológica de la Universidad de Alicante, Alicante (España); PBLA: Colección Pablo Bercedo \& Lucía Arnáiz, Devesa de Cureño, León (España); JLR: Colección J.L. Ruiz, Ceuta (España).

Appendix 1.- Material examined of Tropinota hirta (Poda von Neuhaus, 1761). The acronyms used are as follows: MNCN: Museo Nacional de Ciencias Naturales-CSIC, Madrid (Spain); CEUA: Entomological Collection of the University of Alicante, Alicante (Spain); PBLA: Pablo Bercedo \& Lucía Arnáiz collection, Devesa de Cureño, León (Spain); JLR: J.L. Ruiz collection, Ceuta (Spain).

ESPAÑA: ALICANTE: 2 ejs.: "Font Roja (Alcoy), Alicante, 28-3-1993, leg. J.R. Verdú" / "Cetoniidae, Tropinota (Epicometis) hirta (Poda, 1761), E. Micó det. (2006)" (CEUA). HUESCA: 1 ej.: "S. Juan de la Peña, 1220 m, Prov. de Huesca" / "Exp. Inst. Esp. , 4-VII-1943" / "MNCN_Ent, 98391" (MNCN); 1 ej.: "S. Juan de la Peña, 1220 m, Prov. de Huesca" / "Exp. Inst. Esp. , 4-VII-1943" / "Tropinota hirta, Det. Dr. L. Báguena" / "MNCN_Ent, 98390" (MNCN); 4 ejs.: "Selva de Oza, Huesca, 6-VII-1990, P. Bercedo leg." (PBLA). NAVARRA: 1 ej.: "Ochagavia, Valle Salazar, Prov. de Navarra" / "Exp. Inst. Esp. , 28-VI-1947” / "Tropinota hirta, Det. Dr. L. Báguena" / "MNCN_Ent, 98392” (MNCN); 1 ej.: "Ochagavia" / "MNCN_Ent, 98393" (MNCN).

FRANCIA: 1 ej.: "Le Londe les Maures, Francia, 15 abril 1993, leg. E. Galante" / "Cetoniidae, Tropinota (Epicometis) hirta (Poda, 1761), Det. E. Micó" (CEUA); 1 ej.: "Viols Le
Fort, Montpellier, 2-junio-1994, leg. J.R. Verdú" / "Cetoniidae, Tropinota (Epicometis) hirta (Poda, 1761), Det. E. Micó” (CEUA).

ITALIA: 2 ejs.: "Mar. (AN): Pianello, piano basale Mte. di Frassani, loc. C. Polli, mt. 230, leg. Biscaccianti, 3-V-99" / "Su Crataegus monogyna" (JLR ex coll. G. Carpaneto).

HUNGRÍA: 2 ejs.: "Dabas - 763, Hungaria centr., 28.4-1.5.1972,

B. Zvarič lgt." / "Epicometis hirta, B. Zvarič det., 17.7.1972” (JLR).

BULGARIA: 2 ejs.: "BG. Maleshevska Mtn. 600 m, 'Morina skala' S from G. Breznitsa, tree traps, VI-2003, S. Lazarov leg." (JLR).

RUMANÍA: 1 ej.: "Dobrudja - Romania, Babadag (Tulcea), 17.IV.2014, S. Ziani leg." (JLR ex coll. S. Ziani).

GRECIA: CRETA: 1 ej.: "Creta, Platania[s]" (JLR ex coll. J. Ferrer).

\section{Apéndice 2.- Descripción de la escultura elitral de Tropinota iec sp. n. y Tropinota hirta. \\ Appendix 2.- Description of the elytral sculpture of Tropinota iec sp. n. and Tropinota hirta.}

\section{$1^{\mathrm{a}}$ interestría o parasutural:}

T. iec: con dos líneas paralelas de puntos finos, pero bien marcados, anexos al margen externo, que se amplía a tres líneas en la región central (discal) de la interestría, separados entre sí a lo sumo su diámetro y muchos de ellos subconfluentes.

T. hirta: con una línea de escasos puntos finos anexos al margen externo, separados entre sí de 1.5 a 3 veces su diámetro, algo más densos en la región central y más separados hacia los extremos, raramente se observan dos líneas de puntos subparalelas en la zona discal.

\section{$2^{\mathrm{a}}$ interestría:}

T. iec: presenta una línea central de fuertes puntos ovalados en forma de herradura $u$ hoz de extremos más o menos cercanos o cerrados (netamente más alargados que en $T$. hirta), densos, confluentes en prácticamente toda la superficie de la interestría, con numerosos puntos simples y finos a ambos lados de los ovalados; en general, predomina la escultura de puntos o marcas en forma de herradura rodeada de puntos simples.

T. hirta: con una línea central de puntos ovalados, con forma de herradura casi cerrada (en algunos casos cerrada), bien separados y no confluentes en la zona central, estos puntos ovalados son de aspecto más alargado y ocasionalmente subconfluentes hacia la base y región distal, con muy escasos y finísimos puntos simples dispersos a los lados; en general, predomina el fondo liso semimate en la interestría.

\section{$3^{\mathrm{a}}$ interestría:}

T. iec: netamente punteada, con una línea de puntos simples finos pero bien impresos, que se hace doble en el tercio basal, separados normalmente entre entre 1 y 3 veces su diámetro.

T. hirta: casi lisa, tanto en la región discal como en la base, sólo con algunos puntos muy finos y dispersos, irregularmente alineados, separados normalmente entre 3.5 y 6 veces su diámetro.

\section{$4^{\mathrm{a}}$ interestría:}

T. iec: punteado similar a la $2^{\mathrm{a}}$ interestría (que es más ancha), aunque con los puntos un poco más densos, tanto los falciformes como los simples, haciéndose a su vez algo más densos y difusos hacia el ápice.

T. hirta: punteado igualmente similar a la $2^{\mathrm{a}}$ interestría (también más ancha), con las marcas falciformes un poco más próximas y densas en el tercio apical, donde ocasionalmente algunas confluyen, y casi desapareciendo en la región declive distal.

\section{$5^{\mathrm{a}}$ interestría:}

T. iec: con una línea irregular bien marcada de puntos falciformes similares a los de la $2^{\mathrm{a}}$ interestría, aunque de menor diámetro y un poco más separados, situada anexa a su borde interno, y escasos puntos simples intercalados entre los falciformes.

T. hirta: casi lisa, sin apenas puntos falciformes (sólo algunos dispersos) y escasos puntos simples más o menos alineados longitudinalmente, separados más de 5 veces su diámetro.

\section{$6^{\mathrm{a}}$ interestría y siguientes:}

T. iec: A partir de la $6^{\mathrm{a}}$ interestría no se distinguen más estrías y el punteado está constituido por puntos falciformes más o menos cerrados en su borde distal, relativamente densos, separados entre 1 y 2.5 veces su diámetro, entre los que se intercalan muy escasos puntos simples y finos, con la mayor densidad en los tercios basal y apical, en este último y sobre todo en la región declive los puntos falciformes se hacen irregulares, subconfluentes y de aspecto subrugoso.

T. hirta: A partir de la $6^{\mathrm{a}}$ interestría no se distinguen más estrías y el punteado es muy escaso, constituido mayoritariamente por puntos simples dispersos, separados entre 2 y 7 veces sus diámetro, sólo con algún punto falciforme disperso, un poco más denso e irregular en la región declive apical y en la región humeral, donde el tegumento puede presentar algunas arrugas difusas. 